\title{
Orbital Exchange Calculations of Chemical Bonding in Some Molecules Containing Carbon
}

\author{
Paul B. Merrithew ${ }^{\mathrm{a}}$ \\ PO Box 120, Amherst, New Hampshire 03031-0120 USA
}

\begin{abstract}
The purpose of this paper is to extend the application of the orbital exchange method to a series of molecules containing carbon. The paper describes the calculation of bond length, bond strength and dipole moment in ethane, ethylene, acetylene, benzene, allene, hydrogen cyanide, formaldehyde, floromethane, tetrafloromethane and floromethylidyne (CF). This work explains how the s bonding orbital coefficients in such molecules as ethylene and acetylene are maximized to enable shorter and stronger carbon-carbon bonds. Pi orbital resonance of the form $[\mathrm{C}-\mathrm{C}+, \mathrm{CC}, \mathrm{C}+\mathrm{C}-]$ in ethylene, acetylene, and benzene is described and quantified. Pi orbital resonance in $\mathrm{HCN}$ [CN,C+N-] and $\mathrm{H}_{2} \mathrm{CO}[\mathrm{CO}, \mathrm{C}+\mathrm{O}-]$ and sigma orbital resonance in $\mathrm{H}_{3} \mathrm{CF}\left[\mathrm{H}_{3} \mathrm{CF}\right.$, $\left.\mathrm{H}_{3} \mathrm{C}+\mathrm{F}-\right], \mathrm{CF}_{4}$ and $\mathrm{CF}$ is quantified. Except for $\mathrm{HC}$ bonds, calculated bond lengths are within $0.005 \AA$ of observed values. Calculated molecular energies are within $2 \%$.
\end{abstract}

\section{INTRODUCTION}

The orbital exchange method ${ }^{1}$ for calculating the chemical bond does not assume that the bonding electrons can be completely distinguished. That the overlapping electrons cannot be completely distinguished in the overlap region has implications beyond a straightforward reduction in kinetic energy. A bonding orbital need only to be made orthogonal to the core electrons of the atom to which it is bonding to the extent that it can be identified as representing an electron on an opposing atom. Similarly, non-bonding electrons need only be made orthogonal to the bonding orbital from an opposing atom to the extent that the bonding orbital is identified as from an opposing atom. The orbital exchange method permits significant latitude in the selection of hybrid orbital coefficients, since, at maximum overlap, a bonding atom can only be unambiguously identified to the extent of 0.5. For example, a traditional sp3 hybrid orbital can be treated as an sp hybrid orbital.

The orbital exchange method permits the summation of all interactions with a given bonding orbital provided that account is taken for simultaneous overlaps. This provides for seamless treatment of interactions with the once-removed, twice-removed, and etc. atoms in a molecule or lattice.

The orbital exchange methods utilized in the calculation of bonding in some simple molecules were described in detail in an earlier paper ${ }^{1}$. The purpose of this paper is to expand the application of orbital exchange method to some somewhat more complex molecules and to introduce some new concepts.

a Electronic mail: pmerrithew@aol.com 


\section{METHODS}

\section{A. Hybrid Orbital Coefficients}

Hybrid orbitals are of the form $\phi=f_{s} 2 s+f p_{b} 2 p_{z}$. The s orbital coefficient is maximized since this generally has the effect of lowering the overlap with the opposite bonding orbital. Lower overlaps are associated with increased bond energy since the maximum of overlap (overlap $=1.0$ ) is reached at a shorter bond length. Typically, shorter bond lengths imply higher bond energy.

As mentioned above, the extent that a given electron can be identified as associated with one of the two bonding atoms impacts the range of possible s orbital coefficients. At maximum overlap, a given electron can only be unambiguously associated with a given atom to the extent of 0.5 . Traditional $\mathrm{sp}^{3}$ orbitals, associated with 4 coordination, can be considered as sp orbitals with $\mathrm{fs}_{\mathrm{b}} \mathrm{fs}_{\mathrm{b}}=0.5$ at overlap $=1.0$. Traditional $\mathrm{sp}^{2}$ orbitals, associated with 3 coordination, have $\mathrm{fs}_{\mathrm{b}} \mathrm{fs}_{\mathrm{b}}=0.667$ at overlap $=1.0$.

For multi-coordinate atoms, all bonding hybrid orbitals need not be identical. One or more of the bonding orbitals can acquire s character from the other orbitals if this results in maximizing the total energy. For example, in $\mathrm{HCCH}$, it is energetically favorable for the $\mathrm{CC}$ bond to be as short as possible. Therefore, the $\mathrm{CC}$ bonding orbitals acquire s character from the $\mathrm{CH}$ bonding orbitals. Such acquisition is limited. The $\mathrm{CC}$ bonding orbital can only acquire $\mathrm{s}$ character from the $\mathrm{CH}$ bonding orbitals to the extent that both bond simultaneously. Table I illustrates the logic for determining $\mathrm{fs}_{\mathrm{b}} \mathrm{f} \mathrm{s}_{\mathrm{b}}$ when one bond of two is preferred in a two-coordinate situation, such as that for $\mathrm{CC}$ in $\mathrm{HCCH}$. Notice that $\mathrm{fs}_{b} \mathrm{fs}_{\mathrm{b}}$ of the $\mathrm{CC}$ bonding orbital is limited because, to the extent that both the $\mathrm{CC}$ and $\mathrm{CH}$ bonds are both not bonding, fsb fs $\mathrm{fs}_{\mathrm{b}}$ must equal 0.5 to meet orthogonality requirements. Table II illustrates the logic for determining fs $\mathrm{fs}_{\mathrm{b}}$ when one bond of three is preferred in a 3-coordinate situation, such as that for $\mathrm{CC}$ in $\mathrm{H}_{2} \mathrm{CCH}_{2}$. Table III illustrates the logic for determining $f_{s_{b}} f_{b}$ when one bond of four is preferred in a 4coordinate situation, such as that for $\mathrm{C}$ in $\mathrm{H}_{3} \mathrm{CCH}_{3}$. Table IV illustrates the logic for determining $\mathrm{fs}_{\mathrm{b}} \mathrm{fs} \mathrm{b}$ when two bonds of three are preferred in a 3-coordinate situation, such as that for $\mathrm{CC}$ in benzene.

Table I. Calculation of s bonding hybrid orbital coefficients fsb for symmetries of the form XCY with Y favored.

\begin{tabular}{|c|c|c|c|c|c|c|c|}
\hline & & \multicolumn{3}{|c|}{ Fraction s for } & \multicolumn{3}{|c|}{$\mathbf{f s}_{\mathbf{b}} \mathbf{f s}_{\mathbf{b}}$ Contribution for } \\
\hline Bonding & Probability & All & Favored & Not & All & Favored & Not \\
\hline $\mathrm{Y} \quad \mathrm{X}$ & & same & & Favored & same & & Favored \\
\hline $\mathrm{b}$ & 0.25 & 0.5 & 1.0 & 0.0 & 0.12500 & 0.25000 & 0.00000 \\
\hline $\mathrm{b} \quad \mathrm{nb}$ & 0.25 & 1.0 & 1.0 & 1.0 & 0.25000 & 0.25000 & 0.25000 \\
\hline $\mathrm{nb} \quad \mathrm{b}$ & 0.25 & 1.0 & 1.0 & 1.0 & 0.25000 & 0.25000 & 0.25000 \\
\hline $\mathrm{nb} \quad \mathrm{nb}$ & 0.25 & 0.5 & 0.5 & 0.5 & 0.12500 & 0.12500 & 0.12500 \\
\hline Totals & 1.000 & & & & 0.75000 & 0.87500 & 0.62500 \\
\hline
\end{tabular}

Bonding(b). Not bonding(nb). Probability of a single bond bonding is 0.5 . Probability of two bonding is $0.50 .5=0.25$. Opposing bonding(b) share $\mathrm{s}$. 
Table II. Calculation of s bonding hybrid orbital coefficients fsb for symmetries of the form $\mathrm{X}_{2} \mathrm{CY}$ with Y favored.

\begin{tabular}{|c|c|c|c|c|c|c|c|c|}
\hline \multirow{2}{*}{\multicolumn{2}{|c|}{ Bonding }} & \multirow{3}{*}{ Probability } & \multicolumn{3}{|c|}{ Fraction $\mathrm{s}$ for } & \multicolumn{3}{|c|}{$\mathbf{f S}_{\mathbf{b}} \mathbf{f S}_{\mathbf{b}}$ Contribution for } \\
\hline & & & \multirow{2}{*}{$\begin{array}{c}\text { All } \\
\text { same }\end{array}$} & \multirow[t]{2}{*}{ Favored } & \multirow{2}{*}{$\begin{array}{l}\text { Not } \\
\text { Favored }\end{array}$} & \multirow{2}{*}{$\begin{array}{c}\text { All } \\
\text { same }\end{array}$} & \multirow[t]{2}{*}{ Favored } & \multirow{2}{*}{$\begin{array}{l}\text { Not } \\
\text { Favored }\end{array}$} \\
\hline $\mathrm{Y}$ & $X$ & & & & & & & \\
\hline $\mathrm{b}$ & $2 b$ & 0.125 & 0.3333 & 1.0 & 0.0 & 0.04167 & 0.12500 & 0.00000 \\
\hline $\mathrm{b}$ & $1 \mathrm{~b}, 1 \mathrm{nb}$ & 20.125 & 0.5 & 0.75 & 0.375 & 0.12500 & 0.18750 & 0.09375 \\
\hline $\mathrm{b}$ & $2 \mathrm{nb}$ & 0.125 & 1.0 & 1.0 & 1.0 & 0.12500 & 0.12500 & 0.12500 \\
\hline $\mathrm{nb}$ & $2 b$ & 0.125 & 1.0 & 1.0 & 1.0 & 0.12500 & 0.12500 & 0.12500 \\
\hline $\mathrm{nb}$ & $1 \mathrm{~b}, 1 \mathrm{nb}$ & 20.125 & 0.75 & 0.75 & 0.75 & 0.18750 & 0.18750 & 0.18750 \\
\hline $\mathrm{nb}$ & $2 \mathrm{nb}$ & 0.125 & 0.5 & 0.5 & 0.5 & 0.06250 & 0.06250 & 0.06250 \\
\hline \multicolumn{2}{|c|}{ Totals } & 1.000 & & & & 0.66667 & 0.81250 & 0.59375 \\
\hline
\end{tabular}

Bonding(b). Not bonding(nb). Probability of a single bond bonding is 0.5 . Probability of all three bonding is $0.50 .50 .5=0.125$. Opposing bonding(b) share s. Opposing not bonding(nb) are half (0.5) s. In the pseudo-trigonal $\mathrm{X}_{2} \mathrm{CY}$ geometry, adjacent bonds oppose to the extent of $1 / 2\left[\cos \left(60^{\circ}\right)=0.5\right]$.

Table III. Calculation of $s$ bonding hybrid orbital coefficients fsb for symmetries of the form $\mathrm{X}_{3} \mathrm{CY}$.

\begin{tabular}{|c|c|c|c|c|c|c|c|}
\hline \multirow{2}{*}{ Bonding } & \multirow{3}{*}{ Probability } & \multicolumn{3}{|c|}{ Fraction $\mathrm{s}$ for } & \multicolumn{3}{|c|}{$\mathbf{f s}_{\mathbf{b}} \mathbf{f S}_{\mathbf{b}}$ Contribution for } \\
\hline & & \multirow{2}{*}{$\begin{array}{c}\text { All } \\
\text { same }\end{array}$} & \multirow[t]{2}{*}{ Favored } & \multirow{2}{*}{$\begin{array}{l}\text { Not } \\
\text { Favored }\end{array}$} & \multirow{2}{*}{$\begin{array}{c}\text { All } \\
\text { same }\end{array}$} & \multirow[t]{2}{*}{ Favored } & \multirow{2}{*}{$\begin{array}{l}\text { Not } \\
\text { Favored }\end{array}$} \\
\hline $\mathrm{Y} \quad \mathrm{X}$ & & & & & & & \\
\hline $3 b$ & 0.0625 & 0.25 & 1.0 & 0.0 & 0.01563 & 0.06250 & 0.00000 \\
\hline b $2 b, 1 n b$ & 30.0625 & 0.3333 & 0.6667 & 0.2222 & 0.06250 & 0.12500 & 0.04167 \\
\hline b $\quad 1 b, 2 n b$ & 30.0625 & 0.5 & 0.6667 & 0.4444 & 0.09375 & 0.12500 & 0.08333 \\
\hline $3 n b$ & 0.0625 & 1.0 & 1.0 & 1.0 & 0.06250 & 0.06250 & 0.06250 \\
\hline $\mathrm{nb}$ & 0.0625 & 0.5 & 0.5 & 0.5 & 0.03125 & 0.03125 & 0.03125 \\
\hline $\mathrm{nb} \quad 2 \mathrm{~b}, 1 \mathrm{nb}$ & 30.0625 & 0.4166 & 0.4166 & 0.4166 & 0.07812 & 0.07812 & 0.07812 \\
\hline $\mathrm{nb} \quad 1 \mathrm{~b}, 2 \mathrm{nb}$ & 30.0625 & 0.6666 & 0.6666 & 0.6666 & 0.12500 & 0.12500 & 0.12500 \\
\hline $\mathrm{nb} \quad 3 \mathrm{nb}$ & 0.0625 & 0.5 & 0.5 & 0.5 & 0.03125 & 0.03125 & 0.03125 \\
\hline Totals & 1.000 & & & & 0.500000 & 0.640625 & 0.453125 \\
\hline
\end{tabular}

Bonding(b). Not bonding(nb). Probability of a single bond bonding is 0.5 . Probability of all four bonding is $0.50 .50 .50 .5=0.0625$. Opposing bonding(b) share $\mathrm{s}$. Opposing not bonding(nb) are half $(0.5) \mathrm{s}$. In the pseudo-tetrahedral $\mathrm{X}_{3} \mathrm{CY}$ geometry, adjacent bonds oppose to the extent of $1 / 3$ [cos $\left(180^{\circ}-109.47^{\circ}\right)=$ 0.3333]. 
Table IV. Calculation of $s$ bonding hybrid orbital coefficients fsb for symmetries of the form $\mathrm{X}_{2} \mathrm{CY}$ with $\mathrm{X}$ favored.

\begin{tabular}{|c|c|c|c|c|c|c|c|}
\hline & \multicolumn{4}{|c|}{ Fraction $s$ for } & \multicolumn{3}{|c|}{$\mathbf{f S}_{\mathbf{b}} \mathbf{f S}_{\mathbf{b}}$ Contribution for } \\
\hline Bonding & Probability & All & Favored & Not & All & Favored & Not \\
\hline $\mathrm{X} \quad \mathrm{Y}$ & & same & (left of X) & Favored & same & & Favored \\
\hline $\mathrm{b}, \mathrm{b} \quad \mathrm{b}$ & 0.125 & 0.3333 & 0.5 & 0.0 & 0.04167 & 0.06250 & 0.00000 \\
\hline $\mathrm{b}, \mathrm{b} \mathrm{nb}$ & 0.125 & 0.5 & 0.75 & 0.0 & 0.06250 & 0.09375 & 0.00000 \\
\hline b, nb b & 0.125 & 0.5 & 0.75 & 0.0 & 0.06250 & 0.09375 & 0.00000 \\
\hline $\mathrm{b}, \mathrm{nb} \mathrm{nb}$ & 0.125 & 1.0 & 1.0 & 1.0 & 0.12500 & 0.12500 & 0.12500 \\
\hline $\mathrm{nb}, \quad \mathrm{b}$ & 0.125 & 1.0 & 1.0 & 1.0 & 0.12500 & 0.12500 & 0.12500 \\
\hline $\mathrm{b}, \mathrm{nb} \mathrm{nb}$ & 0.125 & 0.75 & 0.75 & 0.75 & 0.09375 & 0.09375 & 0.09375 \\
\hline $\mathrm{nb}, \mathrm{b} \mathrm{nb}$ & 0.125 & 0.75 & 0.75 & 0.75 & 0.09375 & 0.09375 & 0.09375 \\
\hline $\mathrm{nb}, \mathrm{nb} \mathrm{nb}$ & 0.125 & 0.5 & 0.5 & 0.5 & 0.06250 & 0.06250 & 0.06250 \\
\hline Totals & 1.000 & & & & 0.66667 & 0.75000 & 0.50000 \\
\hline
\end{tabular}

Bonding(b). Not bonding(nb). Probability of a single bond bonding is 0.5 . Probability of all three bonding is $0.50 .50 .5=0.125$. Opposing bonding(b) share s. Opposing not bonding(nb) are half $(0.5) \mathrm{s}$. In the pseudo-trigonal $\mathrm{X}_{2} \mathrm{CY}$ geometry, adjacent bonds oppose to the extent of $1 / 2\left[\cos \left(60^{\circ}\right)=0.5\right]$.

\section{B. Non-Coincident Bonding}

Typically, primary and secondary bonds are coincident. Total overlap is found by summing primary and secondary overlaps while excluding the extent of coincidence. However, there are instances where the secondary bonds cannot be coincident. This occurs when the primary bond is partially dual.

Dual bonding occurs when there is more than one electron pair available for sigma bonding. Full dual bonding is observed in many di-atomics such as $\mathrm{C}_{2}, \mathrm{~N}_{2}$ and $\mathrm{O}_{2}$. Partial dual bonding occurs when a second electron pair is available to a partial extent. This occurs, for example, in the $\mathrm{CC}$ bond in $\mathrm{H}_{2} \mathrm{CCH}_{2}$. C has the $2 \mathrm{~s}^{2} 2 \mathrm{p}^{2}$ configuration. When bonding in the pseudo trigonal configuration, such as in $\mathrm{H}_{2} \mathrm{CCH}_{2}$, one of the $2 \mathrm{~s}$ does not have be completely promoted to $2 p$ to meet the orthogonality requirement. This leaves what can be described as a $2 \mathrm{~s}^{1.125} 2 \mathrm{p}^{2.875}$ configuration. The $2 \mathrm{~s}$ is not promoted to $2 \mathrm{p}$ to the extent that all three $\mathrm{C}$ bonds are not bonding $(0.50 .50 .5=0.125)$. Each $\mathrm{C} 2 \mathrm{~s}$ is available for $\mathrm{CC}$ dual bonding to the extent of 0.25 (when the $\mathrm{CH}$ bonds are bonding). Another example is the $\mathrm{CC}$ bond in $\mathrm{HCCH}$. The $2 \mathrm{~s}$ is not promoted to $2 p$ to the extent that the two $\mathrm{C}$ bonds are bonding $(0.50 .5=0.25)$. Here each $\mathrm{C} 2 \mathrm{~s}$ is available for $\mathrm{CC}$ dual bonding to the extent of 0.5 (when the $\mathrm{CH}$ bond is bonding).

Consider the secondary bonding in the $\mathrm{H}_{2} \mathrm{CCH}_{2}$ example. The 2s orbital on the left-hand $\mathrm{C}$ cannot bond to the $\mathrm{Hs}$ on the right-hand $\mathrm{C}$ coincident with the bonding of right-hand $\mathrm{C} 2 \mathrm{~s}$ to the Hs on the left. This is because the left-hand $\mathrm{CH}$ bonds are not necessarily bonding coincident with the bonding of the right-hand $\mathrm{CH}$ bonds. The left-to-right $\mathrm{HC}$ secondary bonds are only coincident with the right-to-left $\mathrm{HC}$ secondary bonds to the extent of 0.25 . Both the left-to-right and right-to-left $\mathrm{HC}$ secondaries bond (and add to the total bond energy) but do not do so in a 
coincident manner. The left-to-right and right-to-left HC secondaries cannot both contribute completely to the maximum overlap total. Only 0.25 of one side contributes to the total.

It should be noted that, when the primary bond is dual, there can be secondary bonding to each of the orbitals with sigma symmetry. In the $\mathrm{H}_{2} \mathrm{CCH}_{2}$ example, there can be a secondary bond between the $\mathrm{H} 1 \mathrm{~s}$ and the $\mathrm{C}$ sp or a secondary bond between the $\mathrm{H} 1 \mathrm{~s}$ and the $\mathrm{C} 2 \mathrm{~s}$. The secondary bond between the $\mathrm{H}$ 1s and the $\mathrm{C} 2 \mathrm{~s}$ is to be favored since this secondary bond is not coincident with the primary to the extent of the secondary bond between the $\mathrm{H} 1 \mathrm{~s}$ and the $\mathrm{C} \mathrm{sp}$ (The $\mathrm{C} 2 \mathrm{~s}$ to $\mathrm{C} 2 \mathrm{~s}$ primary bond only occurs to the extent of 0.25 ). Less coincidence between the primary and secondary bonds implies a higher secondary bond energy.

Consideration of non-coincident bonding in the calculation of secondary interactions has a small, but significant, impact on the bond length results. For bonds that have a partial dual component, the assumption that all secondary bonds are coincident results in erroneously long calculated bond lengths.

\section{Resonance}

Both sigma and pi electrons can resonate. Resonance frequently takes the form $\left[\mathrm{XY}, \mathrm{X}^{+} \mathrm{Y}^{-}\right]$and sometimes $\left[\mathrm{X}^{-} \mathrm{Y}^{+}, \mathrm{XY}, \mathrm{X}^{+} \mathrm{Y}^{-}\right]$. The relative population of uncharged and charged species need not be $[0.5,0.5]$ or $[0.25,0.5,0.25]$. For resonances of the type $\left[\mathrm{XY}, \mathrm{X}^{+} \mathrm{Y}^{-}\right]$ frequently the relative populations of neutral and anionic species are $[0.75,0.25]$.

Adjacent bonds cannot both support resonance as this would result in the possibility of an energetically unfavorable doubly charged species. For example, in benzene, only two of the six bonds can host a pi resonance. Resonances which might result in the anionic and cationic species being separated by more than one bond also do not occur as these are also very energetically unfavorable.

A resonating electron has the kinetic energy of an electron in an orbital which overlaps totally (overlap $=1.0$ ) with the opposite bonding orbital. This is particularly significant for pi resonance where overlap seldom approaches 1.0. Reduced kinetic energy, however, is not the only factor which makes resonance energetically favorable. The potential energy of the charged species, $\mathrm{X}^{+} \mathrm{Y}^{-}$, is also very important in determining the favorability of resonance. The potential energy associated with $\mathrm{X}^{+} \mathrm{Y}^{-}$depends on the electronic configuration of $\mathrm{Y}^{-}$.

Atoms with non-bonding electrons typically have two configurations; a "bonding" configuration when all of the bonds to coordinated atoms are bonding and a "not-bonding" configuration when any of the bonds are not bonding. The latter configuration meets the orthogonality requirements (valence orthogonality). For example, $\mathrm{N}_{2}$ has a bonding configuration of $2 s^{2} 2 p_{z} 2 p_{\pi}^{2}$ (same as the atom) and a not-bonding configuration of $2 s p_{o} 2 s 2 p_{z} 2 p_{\pi}^{2}$, where $s p_{o}$ is the "opposing" hybrid orbital orthogonal to the bonding orbital on the opposite N. Since $\mathrm{N}_{2}$ is bonding for 0.5 (fraction_bonding=0.5), the former configuration occurs to the extent of 0.5 and the latter to 0.5 .

$\mathrm{N}$ in $\mathrm{HCN}$ has configurations the same as those of the $\mathrm{N}$ in $\mathrm{N}_{2}$. The $\mathrm{CN}$ in $\mathrm{HCN}$ has a pi resonance of the form $\left[\mathrm{CN}, \mathrm{C}^{+} \mathrm{N}^{-}\right]$. The potential energy associated with the $\mathrm{N}$ bonding configuration acquiring an extra pi electron is more favorable than the not-bonding configuration acquiring an extra pi electron. Therefore, $\mathrm{CN}$ has a pi resonance when the $\mathrm{CN}$ sigma bond is bonding (i.e. for 0.5 ). The relative populations of $\mathrm{CN}$ and $\mathrm{C}^{+} \mathrm{N}^{-}$are $[0.75,0.25]$. The $\mathrm{CO}$ pi resonance in $\mathrm{H}_{2} \mathrm{CO}$ is similar to the pi resonance in $\mathrm{HCN}$.

The $\mathrm{CF}$ bonds in $\mathrm{CF}_{4}$ and $\mathrm{H}_{3} \mathrm{CF}$ exhibit sigma bond resonances. These occur when $\mathrm{F}$ is in the not bonding configuration. 


\section{RESULTS}

The results are summarized in Table V. As in the previous work, the atomic orbitals of Duncanson and Coulson ${ }^{2}$ have been utilized. The quantities Duncanson and Coulson call $\mu$ and $\mu \mathrm{c}$ (These are equivalent to the effective nuclear charge [or orbital scale factor] for $2 \mathrm{~s}$ and $2 p$ electrons.), are increased by factors (called fact herein) ranging from 1.01 to 1.055 consistent with previous work ${ }^{1}$.

\section{Table V. Orbital Exchange Calculation Results for Some Molecules Containing Carbon}

\begin{tabular}{|c|c|c|c|c|}
\hline Molecule & $\begin{array}{l}\text { Observed/ } \\
\text { Calculated }\end{array}$ & $\begin{array}{c}\text { Configurations } \\
\left.\text { (1 } \mathrm{s}^{2} \text { omitted }\right)\end{array}$ & Resonance & Bonds \\
\hline $\begin{array}{l}\text { Ethane } \\
\mathrm{H}_{3} \mathrm{CCH}_{3}\end{array}$ & $\begin{array}{c}\text { CC length } \\
1.535 / 1.531 \\
\text { HC length } \\
1.094 / 1.13 \\
\text { energy } \\
29.18 / 28.98\end{array}$ & $\begin{array}{c}C 2 \mathrm{~s} 2_{2} \mathrm{p}_{\mathrm{z}} 2 \mathrm{p}_{\perp}{ }^{2} \\
\mathrm{C} \mathrm{fs}_{\mathrm{bc}} \mathrm{fs}_{\mathrm{bc}}=0.641 \\
\mathrm{C} \mathrm{fs}_{\mathrm{bH}} \mathrm{fs}_{\mathrm{bH}}=0.453 \\
\mathrm{fact}_{2 \mathrm{~s}, 2 \mathrm{p}}=1.055 \\
\mathrm{H}: 1 \mathrm{~s}(\text { polarized }) \\
\mathrm{H} \mathrm{fs}_{\mathrm{b}} \mathrm{fs}_{\mathrm{b}}=0.983\end{array}$ & no resonance & $\mathrm{CC} \sigma$ \\
\hline $\begin{array}{l}\text { Ethylene } \\
\mathrm{H}_{2} \mathrm{CCH}_{2}\end{array}$ & $\begin{array}{c}\text { CC length } \\
1.339 / 1.340 \\
\\
\text { HC length } \\
1.087 / 1.105 \\
\text { energy } \\
23.35 \pm 0.16 / \\
23.54\end{array}$ & 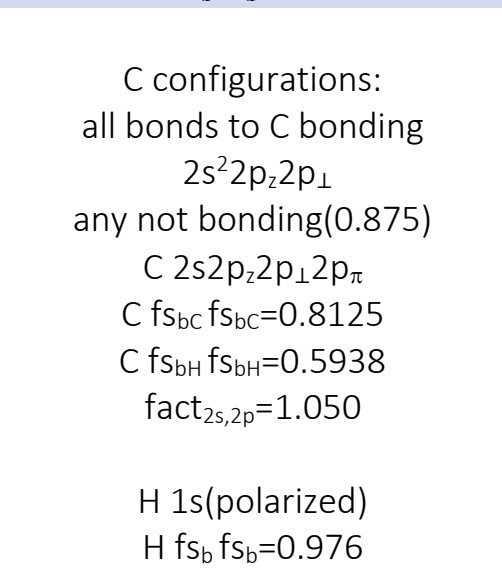 & $\begin{array}{c}{[\mathrm{C}-\mathrm{C}+\mathrm{CC}, \mathrm{C}+\mathrm{C}-]} \\
\pi_{\text {resonance }} \\
\\
\text { fraction } \mathrm{s} \Rightarrow \mathrm{p} \text { on one } \\
\text { side }= \\
1.0-0.5 \cdot 0.5 \cdot 0.5= \\
0.875\end{array}$ & $\begin{array}{c}\mathrm{CC} \sigma \text {, partial dual } \sigma \\
\text { when both } \mathrm{H} \\
\text { on both sides are } \\
\text { bonding } \\
2 \pi_{\text {resonance when } s} \Rightarrow \mathrm{p} \text { on } \\
\text { both sides. } \\
1 \pi_{\text {resonance }} \text { when } \mathrm{s} \Rightarrow \mathrm{p} \text { on } \\
\text { just one side. } \\
\mathrm{HC} \sigma \\
\mathrm{H}: 1 \mathrm{~s} \text { polarized with } 2 \mathrm{p}_{z} \\
\text { [2p fact }=2.90,1 \mathrm{~s} \\
\text { fact }=1.09]\end{array}$ \\
\hline $\begin{array}{l}\text { Acetylene } \\
\mathrm{HCCH}\end{array}$ & $\begin{array}{c}\text { CC length } \\
1.203 / 1.195 \\
\\
\text { HC length } \\
1.060 / 1.115 \\
\\
\text { energy } \\
17.01 \pm 0.14 / \\
17.20\end{array}$ & $\begin{array}{c}C \text { configurations: } \\
\text { both bonds to } C \text { bonding } \\
2 s^{2} 2 p_{z} 2 p_{\pi} \\
\text { any not bonding }(0.753) \\
C 2 s_{2} 2 p_{z} 2 p_{\pi}^{2} \\
C f_{s c} f_{s b c}=0.875 \\
C f_{s b H} f_{s h H}=0.625 \\
\text { fact }_{2 s, 2 p}=1.040 \\
2 \pi \text { bonding orbitals on } C \text { when } \\
\text { any not bonding }\end{array}$ & $\begin{array}{c}{[\mathrm{C}-\mathrm{C}+\mathrm{CC}, \mathrm{C}+\mathrm{C}-]} \\
\pi_{\text {resonance }} \\
\text { fraction } \mathrm{s} \Rightarrow \mathrm{p} \text { on one } \\
\text { side }=1.0-0.5 \cdot 0.494= \\
0.753\end{array}$ & $\begin{array}{c}\mathrm{CC} \sigma \text {, partial dual } \sigma \\
\text { when } \mathrm{H} \\
\text { on both sides are } \\
\text { bonding } \\
2 \pi_{\text {resonance }} \text { plus } \pi \text { when } \\
\mathrm{s} \Rightarrow \mathrm{p} \text { on both sides. } \\
\text { otherwise } 1 \pi_{\text {resonance }} \\
\mathrm{HC} \sigma \text { (bonding }=0.494) \\
\mathrm{HC} \text { bond does not reach } \\
\text { bonding }=0.5 \\
\mathrm{H}: 1 \mathrm{~s} \text { polarized with } 2 \mathrm{p}_{z}\end{array}$ \\
\hline
\end{tabular}




\begin{tabular}{|c|c|c|c|c|}
\hline Molecule & $\begin{array}{l}\text { Observed/ } \\
\text { Calculated }\end{array}$ & $\begin{array}{c}\text { Configurations } \\
\left(1 s^{2} \text { omitted }\right)\end{array}$ & Resonance & Bonds \\
\hline $\begin{array}{l}\text { Benzene } \\
\mathrm{C}_{6} \mathrm{H}_{6}\end{array}$ & $\begin{array}{c}\text { CC length } \\
1.399 / 1.400 \\
\text { HC length } \\
1.101 / 1.13 \\
\text { energy } \\
57.25 / 57.61\end{array}$ & 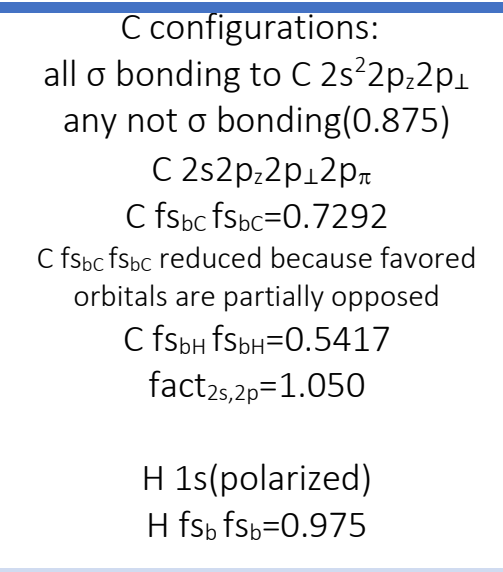 & $\begin{array}{c}{[\mathrm{C}-\mathrm{C}+, \mathrm{CC}, \mathrm{C}+\mathrm{C}-][\mathrm{CC}]_{2}} \\
0.3333 \pi_{\text {resonance }}\end{array}$ & $\begin{array}{c}\text { CC } \sigma \text {, partial dual } \sigma \\
\text { when both adjacent CC } \\
\text { are bonding } \\
2 \pi_{\text {resonance for } 0.333} \\
\text { when } s \Rightarrow p \text { on both sides } \\
\pi_{\text {resonance for } 0.333 \text { when }} \\
s \Rightarrow p \text { on one side } \\
2 \pi \text { for } 0.667 \text { when } s \Rightarrow p \\
\text { on both sides (reduced } \\
\text { by common overlap) } \\
\text { HC } \sigma\end{array}$ \\
\hline $\begin{array}{l}\text { Allene } \\
\mathrm{H}_{2} \mathrm{CCCH}_{2}\end{array}$ & $\begin{array}{c}\text { CC length } \\
1.308 / 1.312 \\
\text { HC length } \\
1.087 / 1.10 \\
\text { energy } \\
29.33 / 29.12\end{array}$ & 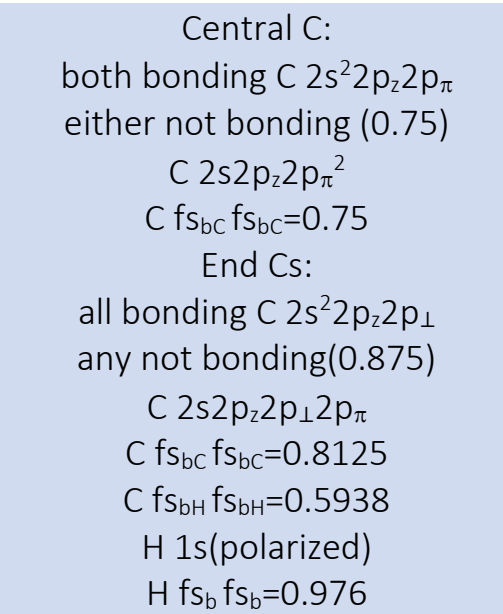 & No resonance & $\begin{array}{c}\text { CC } \sigma \text {, partial dual } \sigma \\
\text { when both } \mathrm{H} \\
\text { bonding and opposite } \\
\text { CC bonding } \\
\pi \text { for } 0.750 .875 \text { (when } \\
s \Rightarrow p \text { on both sides) } \\
0.5 \pi \text { for } 0.250 .875 \\
\text { when } s \Rightarrow p \text { on end } C \\
\text { and } s \nRightarrow p \text { on central } C \\
\text { reduced by } 0.5 \pi \text { overlap }\end{array}$ \\
\hline $\begin{array}{l}\text { Hydrogen } \\
\text { cyanide } \\
\text { HCN }\end{array}$ & $\begin{array}{c}\text { CN length } \\
1.153 / 1.156 \\
\text { HC length } \\
1.066 / 1.093 \\
\text { energy } \\
\text { 13.25/12.98 } \\
\begin{array}{c}\text { Dipole moment } \\
(\mu) \\
\left(\mu_{\text {calc }}=3.04 \mathrm{D}\right. \\
\left.\mu_{\text {expt }}=2.985 \mathrm{D}\right)\end{array}\end{array}$ & 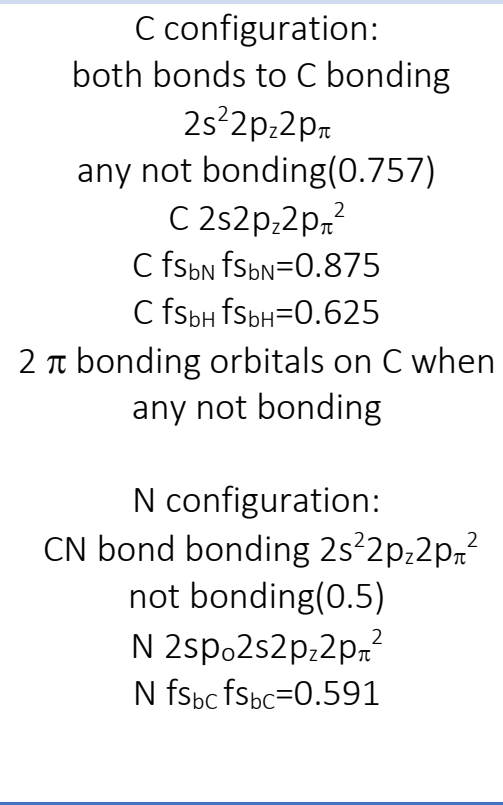 & $\begin{array}{c}{[\mathrm{CN}, \mathrm{C}+\mathrm{N}-]} \\
(0.75,0.25) \\
\pi_{\text {resonance }} \\
\text { Resonance only when } \\
\mathrm{N} \text { configuration Is } \\
2 \mathrm{~s}^{2} 2 \mathrm{p}_{\mathrm{z}} 2 \mathrm{p}_{\pi}^{2} \\
(\mathrm{~s} \nRightarrow \mathrm{p} \text { on } \mathrm{N}) \\
\\
\text { fraction } \mathrm{s} \Rightarrow \mathrm{p} \text { on } \mathrm{C} \\
\text { side }=1.0-0.5 \cdot 0.486= \\
0.757\end{array}$ & $\begin{array}{c}\mathrm{CN} \sigma \text {, partial dual } \sigma \\
\text { when } \mathrm{H} \\
\text { bonding on } \mathrm{C} \\
\mathrm{HC} \sigma \text { (bonding }=0.486 \text { ) } \\
\mathrm{HC} \text { bond does not reach } \\
\text { bonding }=0.5 \\
\mathrm{H}: 1 \mathrm{~s} \text { polarized with } 2 \mathrm{p} \\
\text { when not resonating } \\
2 \pi \text { when } \mathrm{s} \Rightarrow \mathrm{p} \text { on } \mathrm{C}, \pi \\
\text { when } \mathrm{s} \nRightarrow \mathrm{p} \text {. } \\
\text { when resonating } \\
\pi \text { when } \mathrm{s} \Rightarrow \mathrm{p} \text { on } \mathrm{C} \\
\text { plus } 0.5 \pi \text { for } 0.5 \text { (when } \\
\text { not } \mathrm{C}+\text { ) }\end{array}$ \\
\hline
\end{tabular}




\begin{tabular}{|c|c|c|c|c|}
\hline Molecule & $\begin{array}{l}\text { Observed/ } \\
\text { Calculated }\end{array}$ & $\begin{array}{c}\text { Configurations } \\
\text { (1 } \text { s }^{2} \text { omitted) }\end{array}$ & Resonance & Bonds \\
\hline $\begin{array}{l}\text { Formal- } \\
\text { dehyde } \\
\mathrm{H}_{2} \mathrm{CO}\end{array}$ & $\begin{array}{c}\text { CO length } \\
1.208 / 1.208 \\
\text { HC length } \\
1.116 / 1.125 \\
\text { energy } \\
15.59 / 15.76 \\
\left(\mu_{\text {calc }}=2.51 \mathrm{D}\right. \\
\left.\mu_{\text {expt }}=2.332 \mathrm{D}\right)\end{array}$ & 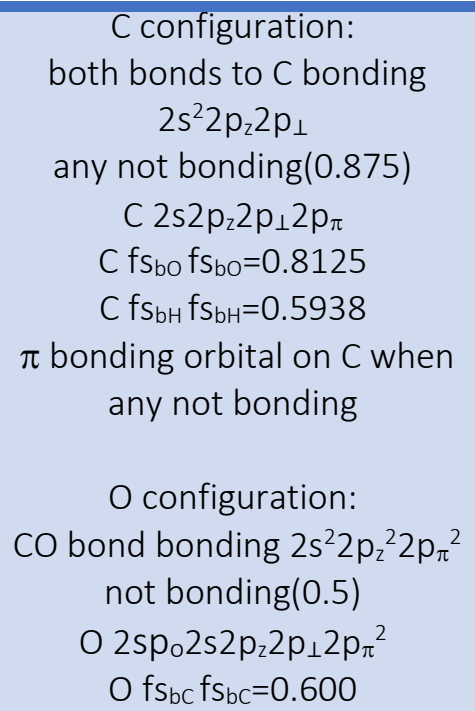 & $\begin{array}{c}\text { [CO,C+O-] } \\
(0.7812,0.2188) \\
(0.2188=0.8750 .25) \\
\pi_{\text {resonance }} \\
\text { Resonance only when } \\
\text { O configuration Is } \\
2 s^{2} 2 p_{z}^{2} 2 p_{\pi}^{2} \\
(s \nRightarrow p \text { on } O) \\
\text { and } s \Rightarrow p \text { on } C \\
\text { fraction } s \Rightarrow p \text { on } C \\
\text { side }=1.0-0.50 .50 .5= \\
0.875\end{array}$ & $\begin{array}{c}\mathrm{CO} \sigma \text {, partial dual } \sigma \\
\text { when } \\
\text { both } \mathrm{H} \text { bonding on } \mathrm{C} \\
\pi_{\text {resonance for } 0.4375} \\
\pi \text { when } \mathrm{s} \Rightarrow \mathrm{p} \text { on } \mathrm{C} \text { and } \\
\text { not resonating ( } 0.875- \\
0.4375 \text { ) } \\
\text { plus, when resonating } \\
0.5 \pi \text { for } 0.5 \text { (when not } \\
\mathrm{C}+\text { ) }\end{array}$ \\
\hline $\begin{array}{l}\text { Floro- } \\
\text { methane } \\
\mathrm{CH}_{3} \mathrm{~F}\end{array}$ & $\begin{array}{c}\text { CF length } \\
1.382 / 1.377 \\
\text { HC length } \\
1.095 / 1.100 \\
\text { energy } \\
17.44 / 17.58 \\
\\
\left(\mu_{\text {calc }}=1.73 \mathrm{D}\right. \\
\left.\mu_{\text {expt }}=1.858 \mathrm{D}\right)\end{array}$ & 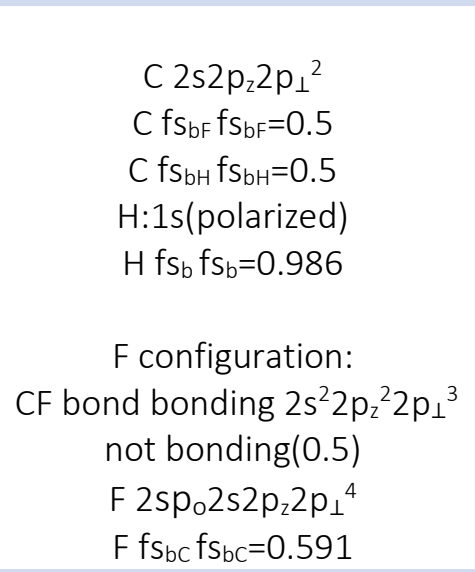 & $\begin{array}{c}{\left[\mathrm{CH}_{3} \mathrm{~F}, \mathrm{C}+\mathrm{H}_{3} \mathrm{~F}-\right]} \\
(0.75,0.25) \\
\sigma_{\text {resonance for } 0.5} \\
\text { fract_ion }=0.25 \\
\text { Resonance only when } \\
\mathrm{F} \text { configuration Is } \\
2 \mathrm{sp}_{\circ} 2 \mathrm{~s} 2 \mathrm{p}_{2} 2 \mathrm{p}_{\perp}{ }^{4} \\
(\mathrm{~s} \Rightarrow \mathrm{p} \text { on } \mathrm{F}) \\
\mathrm{s} \Rightarrow p \text { on } \mathrm{F}=0.5\end{array}$ & $\begin{array}{c}\text { CF } \sigma \\
\text { Overlap calculation: } \\
0.5 \text { fract_ion parallel } \\
\text { bond when C+F-. } \\
\text { serial overlap reduced } \\
\text { by } \\
\text { (1.0-0.5*fract_ion). } \\
\text { Kinetic energy: } \\
0.5 \text { resonance } \\
2-0.5 \text { non-resonance }\end{array}$ \\
\hline $\begin{array}{l}\text { Tetrafloro- } \\
\text { methane } \\
\mathrm{CF}_{4}\left(\mathrm{~T}_{\mathrm{d}}\right)\end{array}$ & $\begin{array}{c}\text { CF length } \\
1.323 / 1.318 \\
\text { energy } \\
5.089 / 5.06 \\
\text { (single CF } \\
\text { bond) }\end{array}$ & $\begin{array}{c}C 2 s_{2} p_{z} 2 p_{\perp}^{2} \\
C f_{b F} f_{b F}=0.5 \\
F \text { configuration: } \\
\text { CF bond bonding } 2 s^{2} 2 p_{z}^{2} 2 p_{\perp}{ }^{3} \\
\text { not bonding }(0.5) \\
F 2 s_{\circ} 2 s_{2} 2 p_{z} 2 p_{\perp}{ }^{4} \\
F \text { f } s_{b c} f s_{b c}=0.589\end{array}$ & $\begin{array}{c}F \quad F \quad F-\quad F \\
{[F-C+F, F C+F-, F C+F, F C+F]} \\
F \quad F \quad F \quad F \\
\text { fract_ion } F-=0.25 \\
\text { Resonance only when } \\
F \text { configuration Is } \\
\text { 2spo2s } 2 p_{z} 2 p_{\perp}{ }^{4} \\
(s \Rightarrow p \text { on } F) \\
s \Rightarrow p \text { on } F=0.5\end{array}$ & $\begin{array}{c}\text { CF } \sigma \\
\text { Overlap calculation: } \\
0.5 \text { fract_ion parallel } \\
\text { bond when C+F-. } \\
\text { serial overlap reduced } \\
\text { by } \\
\text { (1.0-0.5*fract_ion). } \\
\text { Kinetic energy: } \\
20.5 \text { resonance } \\
2 \text { - } 0.75 \text { non-resonance }\end{array}$ \\
\hline
\end{tabular}




\begin{tabular}{|c|c|c|c|c|}
\hline Molecule & $\begin{array}{l}\text { Observed/ } \\
\text { Calculated }\end{array}$ & $\begin{array}{c}\text { Configurations } \\
\text { (1s } \mathrm{s}^{2} \text { omitted) }\end{array}$ & Resonance & Bonds \\
\hline $\begin{array}{l}\text { Floro- } \\
\text { methyl- } \\
\text { idyne } \\
\text { (CF) }\end{array}$ & $\begin{array}{c}\text { CF length } \\
1.272 / 1.269 \\
\text { energy } \\
5.33 \pm 0.11 / 5.40 \\
\left(\mu_{\text {calc }}=0.63 \mathrm{D}\right. \\
\left.\mu_{\text {expt }}=0.645 \mathrm{D}\right)\end{array}$ & 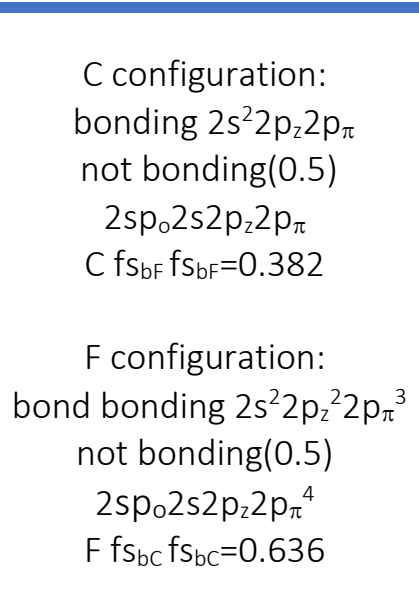 & $\begin{array}{c}{[C F, C+F-]} \\
(0.75,0.25) \\
\sigma_{\text {resonance for } 0.5} \\
\text { fract_ion } \mathrm{F}-=0.25 \\
\text { Resonance only when } \\
\text { F configuration Is } \\
2 s p_{\circ} 2 s 2 p_{z} 2 p_{\perp}{ }^{4}\end{array}$ & $\begin{array}{c}\sigma \text { overlap calculation: } \\
\text { CF } \sigma \text { dual } \\
\text { C+F- } \sigma \\
\text { dual on } \mathrm{C}+\text { side } \\
\text { single on } \mathrm{F} \text { - side } \\
0.5 \text { fract_ion parallel } \\
\text { bond } \\
\text { Kinetic energy: } \\
0.5 \text { resonance } \\
2 \text { non-resonance } \\
\pi \text { bond } \\
\pi \text { orthogonalization } \\
\text { when } \mathrm{s} \Rightarrow \text { p and when } \mathrm{F}-\end{array}$ \\
\hline
\end{tabular}

Bond lengths are in $\AA$. Energy is in eV. Except for $\mathrm{CF}_{4}$, energy here is the total of the bond energies. This energy is calculated from data in the CRC Handbook ${ }^{3}$. Bond lengths are from the CRC Handbook ${ }^{4}$. Dipole moments are from the CRC Handbook ${ }^{5}$. $s \Rightarrow p$ indicates a $2 s$ promoted to $2 p$. Fraction $s \Rightarrow p$ is typically $1.0-0.5 * 0.5=0.75$ for 2 coordinate atoms, $1.0-0.5 * 0.5 * 0.5=0.875$ for 3 coordinate atoms. Terms used in bond counting: a single $\sigma$ or $\pi$ bond entails the left electron bonding to the right as well as the right electron bonding to the left (so a 0.5 bond entails only the electron on one side bonding), a single $\sigma$ or $\pi$ resonance entails only a single electron.

\section{A. Ethane $\left(\mathrm{H}_{3} \mathrm{CCH}_{3}\right)$}

The stability of ethane is maximized by making the $\mathrm{CC}$ bond as short as possible consistent with the possible hybrid orbital coefficients. Shorter bonds are associated with hybrid orbitals with larger s orbital coefficients. The s orbital coefficient for the $\mathrm{CC}$ bond in ethane is set to 0.641 consistent with the analysis summarized in Table III. This results in a calculated CC bond length of $1.531 \AA$, in good agreement with the observed bond length of $1.535 \AA$.

The bond lengths for the HC bonds are calculated to be $1.13 \AA$ vs. the observed value of

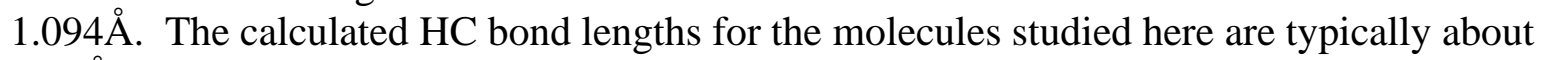
$0.03 \AA$ higher than the observed values.

It is generally difficult to determine the core orthogonalization parameters for "soft" atoms such as $\mathrm{H}$. This issue is discussed in Section IIIA of reference 1. The estimated uncertainty associated with the core orthogonalization of $\mathrm{H}$ is about 0.01 to $0.02 \AA$. Difficulties associated with core orthogonalization do not account for the observed difference between the calculated and observed values for the $\mathrm{HC}$ bond length. Difficulties associated with core orthogonalization lead to uncertainties in the energy of the $\mathrm{HC}$ bond of about 0.05 to $0.08 \mathrm{eV}$ (1 to $2 \%$ ).

In bonding, $\mathrm{H}$ is polarized towards $\mathrm{C}$ by adding electron density of the form of a $2 \mathrm{p}$ orbital with an effective nuclear charge of 2.90 to the $\mathrm{H} 1 \mathrm{~s}$ orbital. Typically, the best bond energy is found when the polarized $\mathrm{H}$ orbital has about $2 \%$ of the added $2 \mathrm{p}$ form. This is a relatively crude method of polarization. The radius of the $1 \mathrm{~s}$ is varied to obtain the maximum bond energy. Polarization has a significant impact on the bond length. Arbitrarily reducing the added $2 p$ function by half reduces the bond length by about $0.02 \AA$ and the energy by about 0.14 $\mathrm{eV}$. 
The calculated total of the bond energies in ethane is $28.98 \mathrm{eV}$. This is to be compared to the observed value of $29.18 \mathrm{eV}$. In this calculation, as well as other calculations discussed in this paper, the energy to promote a 2 s to a $2 p$ is the energy given in Table IV in reference 1.

\section{B. Ethylene $\left(\mathrm{H}_{2} \mathrm{CCH}_{2}\right)$}

The s orbital coefficient for the $\mathrm{CC}$ bond in ethylene is set to 0.8125 consistent with the analysis summarized in Table II. The CC bond in ethylene is dual to the extent that the two HC bonds on each $\mathrm{C}$ are both bonding $(0.50 .50 .50 .5=0.0625)$. The calculated $\mathrm{CC}$ bond length is $1.340 \AA$, in good agreement with the observed bond length of $1.339 \AA$. The calculated total of the bond energies in ethylene is $23.54 \mathrm{eV}$. This is to be compared to the observed value of $23.35 \mathrm{eV}$. Detailed breakdowns of the CC and HC bond calculations in ethylene are shown in Tables VI and VII, respectively.

Each carbon in ethylene has a $\mathrm{p}_{\pi}$ electron to the extent that any of its three sigma bonds is not-bonding $(1.0-0.50 .50 .5=0.875)$. These $\mathrm{p}_{\pi}$ electrons resonate. Although the kinetic energy of a resonating $\mathrm{p}_{\pi}$ electron is more favorable than that of a simple pi bond, resonance is driven primarily by the lower potential energy associated with the $\mathrm{C}^{-} \mathrm{C}^{+}$charge separation (electronelectron repulsions are less). That the lower potential energy associated with charge separation is the primary driver of resonance appears to be general.

\section{Table VI. Components of the $\mathrm{C}=\mathrm{C}$ bond in $\mathrm{H}_{2} \mathrm{CCH}_{2}$ Calculation at $1.3414 \AA$ (Energy in electron volts)}

The configuration of $\mathrm{C}$ is $1 \mathrm{~s}^{2} 2 \mathrm{~s}^{2} 2 \mathrm{p}^{2} . \mathrm{H}_{2} \mathrm{C}=\mathrm{C}$ has a pseudo trigonal planar structure. The configuration of $\mathrm{C}$ in $\mathrm{H}_{2} \mathrm{CCH}_{2}$ is $1 \mathrm{~s}^{2} 2 \mathrm{~s}^{0.125} 2 \mathrm{p}_{\mathrm{z}} 2 \mathrm{p}_{\mathrm{xy}}{ }^{1.875}$. Terminology is as in reference 1. Orbital scale factor for $\mathrm{C}$ is 1.05 . In the limit of complete bonding, fraction $\mathrm{s}$ to $\mathrm{p}$ is typically $1.0-0.5$ $0.5=0.75$ for 2 coordination, $1.0-0.50 .50 .5=0.875$ for 3 coordination.

\begin{tabular}{|c|c|c|c|}
\hline Component & Value & $\begin{array}{l}\text { Overlap } \\
\text { change }\end{array}$ & $\begin{array}{l}\text { Energy } \\
(\mathrm{eV}) \\
\text { change }\end{array}$ \\
\hline \multicolumn{4}{|l|}{ Primary $C=C$ Bond } \\
\hline overlap s-s $_{\text {s. }}$ & 0.4076 & & \\
\hline overlap $_{\mathrm{s}-\mathrm{p}}=$ overlap $_{\mathrm{p}-\mathrm{s}}$ & 0.5019 & & \\
\hline overlap p-p & 0.5766 & & \\
\hline \multicolumn{4}{|c|}{$\begin{array}{l}\text { sigma overlap of primary sp hybrid orbitals with } \mathrm{s} \text { up }\left(\text { overlap }_{\mathrm{sp} / \mathrm{sp}}\right) \\
\text { overlap }_{\mathrm{sp} / \mathrm{sp}}=\mathrm{fs}_{\mathrm{b}} \mathrm{fs}_{\mathrm{b}} \text { overlap } \mathrm{s- \textrm {s }}+\mathrm{fs}_{\mathrm{b}} \mathrm{fp}_{\mathrm{b}} \text { overlap } \mathrm{s}_{\mathrm{p}}+ \\
\mathrm{fp}_{\mathrm{b}} \mathrm{fs}_{\mathrm{b}} \text { overlap } \mathrm{p}_{\mathrm{s}}+\mathrm{fp}_{\mathrm{b}} \mathrm{fp}_{\mathrm{b}} \text { overlap } \mathrm{p}-\mathrm{p} \\
\mathrm{fs}_{\mathrm{b}}=\operatorname{sqrt}(0.8125), \mathrm{fp}_{\mathrm{b}}=\operatorname{sqrt}(1.0-0.8125)\end{array}$} \\
\hline $\begin{array}{l}\text { fraction_bonding when single sp/sp bond }(\mathrm{s} \text { up }) \\
\text { fraction_bonding }_{\mathrm{sp} / \mathrm{sp}}=\text { overlap }_{\mathrm{sp} / \mathrm{sp}} /\left(1+\text { overlap }_{\mathrm{sp} / \mathrm{sp}}\right)\end{array}$ & 0.4539 & & \\
\hline
\end{tabular}


Calculation of Bonding when two $\sigma$ bonding electrons

( $s$ down dual bond)

overlap $_{\mathrm{sp} / \mathrm{s}}=$ overlap $_{\mathrm{s} / \mathrm{sp}}=\mathrm{fs}_{\mathrm{b}}$ overlap $_{\mathrm{s}-\mathrm{s}}+\mathrm{fp}_{\mathrm{b}}$ overlap $_{\mathrm{s}-\mathrm{p}}$

and overlap $_{\mathrm{s} / \mathrm{s}}=$ overlap $_{\mathrm{s}-\mathrm{s}}$

average bonding of each of two pairs fraction_bonding ave $=0.25 \quad 0.3703$

(fraction_bonding $g_{\mathrm{sp} / \mathrm{sp}}+2.0$ fraction_bonding $\mathrm{sp}_{\mathrm{s} / \mathrm{s}}+$ fraction_bonding $\mathrm{s}_{\mathrm{s} / \mathrm{s}}$ )

sum of overlaps of both bonding pairs $=2.0$ (fraction_bonding ave/

(1.0- fraction_bondingave))

simultaneous overlap of $\mathrm{sp} / \mathrm{sp}$ and $\mathrm{s} / \mathrm{s}=$ fraction_bonding $\mathrm{sp} / \mathrm{sp}$

fraction_bonding $\mathrm{s}_{\mathrm{s}} /$ ( 1.0 - fraction_bonding $\mathrm{sp}_{\mathrm{sp}}$

fraction_bonding $\mathrm{s} / \mathrm{s}$ )

simultaneous overlap of sp/s and s/sp = fraction_bonding sp/s $_{\text {s }}$

fraction_bonding $\mathrm{s} / \mathrm{sp} /\left(\right.$ (1.0- fraction_bonding $\mathrm{sp}_{\mathrm{sp}}$

fraction_bonding $\mathrm{s}_{\mathrm{s} / \mathrm{sp}}$ )

overlap of two pair exclusive of coincident bonding $=$

0.8674

sum of overlap of both pairs - overlap of sp/sp and s/s -

overlap of $\mathrm{sp} / \mathrm{s}$ and $\mathrm{s} / \mathrm{sp}$

dual fraction_bonding (fraction_bonding dual $) \quad$ (s down dual) $\quad 0.4645$

factor $=$ fraction_bonding $g_{\text {dual }} /$ fraction_bonding ave $\quad 1.2542$

primary fraction_bonding (fraction_bonding 1 st)

0.4545

fraction_bonding ${ }_{1 \mathrm{st}}=(1.0-0.250 .25)$ fraction_bonding $\mathrm{sp}_{\mathrm{sp}}+$

$(0.250 .25)$ fraction_bonding

primary overlap (overlap 1 st)

0.8333

0.8333

overlap $_{1 \text { st }}=$ fraction_bonding 1 st $/\left(1.0\right.$ - fraction_bonding $\left.{ }_{1 \mathrm{st}}\right)$

Calculation of Sigma Bonding Kinetic Energy Contributions

kinetic energy of hybrid orbital sp-sp bond ( $\left.2 \mathrm{KE}_{\mathrm{sp} / \mathrm{sp}}\right)$ with $\mathrm{s}$ up

6.8654

$\mathrm{KE}_{\mathrm{sp} / \mathrm{sp}}=\left(1 /\left(1+\right.\right.$ overlap $\left.\left._{\mathrm{sp} / \mathrm{sp}}\right)\right)\left(\mathrm{fs}_{\mathrm{b}} \mathrm{fs}_{\mathrm{b}}\right.$ overlap s-s $\mathrm{KE}_{\text {net s-s }}+$

$\mathrm{fs}_{\mathrm{b}} \mathrm{fp}_{\mathrm{b}}$ overlap s-pz $\mathrm{KE}_{\text {net s-pz }}+\mathrm{fp}_{\mathrm{b}} \mathrm{fs}_{\mathrm{b}}$ overlap pz-s $\mathrm{KE}_{\text {net pz-s }}+$

$\mathrm{fp}_{\mathrm{b}} \mathrm{fp}_{\mathrm{b}}$ overlap $\mathrm{pz-s} \mathrm{KE}_{\mathrm{net}} \mathrm{pz}-\mathrm{pz}$ )

kinetic energy of hybrid orbital s-sp bond $\left(2 \mathrm{KE}_{\mathrm{s} / \mathrm{sp}}\right)$

5.0857

$\mathrm{KE}_{\mathrm{s} / \mathrm{sp}}=\left(1 /\left(1+\right.\right.$ overlap $\left.\left._{\mathrm{s} / \mathrm{sp}}\right)\right)\left(\right.$ fs $_{\mathrm{br}}$ overlap s-s $\mathrm{KE}_{\text {net s-s }}+$

$f_{\text {br }}$ overlap s-pz $\left.K E_{\text {net s-pz }}\right)$

$\mathrm{KE}_{\mathrm{sp} / \mathrm{s}}=\mathrm{KE}_{\mathrm{s} / \mathrm{sp}}$

kinetic energy of s-s bond $\left(2 \mathrm{KE}_{\mathrm{s} / \mathrm{s}}\right)$

3.6605

$\mathrm{KE}_{\mathrm{s} / \mathrm{s}}=\left(1 /\left(1+\right.\right.$ overlap $\left.\left._{\mathrm{s} / \mathrm{s}}\right)\right)$ overlap $_{\mathrm{s}-\mathrm{s}} \mathrm{KE}_{\text {net s-s }}$

kinetic energy of dual bond ( $\left.2 \mathrm{KE}_{\text {dual }}\right)$

$\mathrm{KE}_{\text {dual }}=$ factor $\left(0.25 \mathrm{KE}_{\mathrm{s} / \mathrm{s}}+0.25 \mathrm{KE}_{\mathrm{s} / \mathrm{sp}}+0.25 \mathrm{KE}_{\mathrm{sp} / \mathrm{s}}+0.25 \mathrm{KE} \mathrm{sp} / \mathrm{ps}\right)$

(factor defined above)

primary kinetic energy $\left(2 \mathrm{KE}_{1 \mathrm{st}}\right)$

6.8392

6.8392

$\mathrm{KE}_{1 \mathrm{st}}=(1.0-0.250 .25) \mathrm{KE}_{\mathrm{sp} / \mathrm{sp}}+(0.250 .25) \mathrm{KE}_{\text {dual }}$

Orthogonalization Energies

energy to make $\mathrm{C}$ sp orbital orthogonal to opposite $\mathrm{C} 1 \mathrm{~s}^{2}$

$-7.2312$

$\left(\mathrm{KE}_{\phi}-\mathrm{KE}_{\phi}\right)$ where $\phi$ is $\mathrm{C}$ sp made orthogonal, $\phi$ is $\mathrm{C}$ sp 


\begin{tabular}{|c|c|c|}
\hline $\begin{array}{l}\text { energy to make } \mathrm{C} \text { sp orbital orthogonal to opposite } 1 \mathrm{~s}^{2} \text { when not } \\
\text { bonding } \\
\qquad \mathrm{KE}_{\text {core ortho }}=\left(\mathrm{KE}_{\phi}-\mathrm{KE}_{\phi}\right)(1-0.5)\end{array}$ & -3.6156 & -3.6156 \\
\hline $\begin{array}{l}\text { energy to make } \mathrm{C} 2 \mathrm{~s} \text { orbital orthogonal to opposite } \mathrm{C} 1 \mathrm{~s}^{2} \\
\left(\mathrm{KE}_{\phi}-\mathrm{KE} \phi\right) \text { where } \phi \text { is } \mathrm{C} 2 \mathrm{~s} \text { made orthogonal, } \phi \text { is } \mathrm{C} 2 \mathrm{~s}\end{array}$ & -4.4257 & \\
\hline $\begin{array}{l}\text { energy to make } \mathrm{C} 2 \mathrm{~s} \text { orbital orthogonal to opposite } 1 \mathrm{~s}^{2} \text { when not } \\
\text { bonding }\end{array}$ & -0.5132 & -0.5132 \\
\hline \multirow{2}{*}{\multicolumn{3}{|c|}{$\begin{array}{c}\mathrm{KE}_{\text {core_ortho }}=\left(\mathrm{KE}_{\phi}-\mathrm{KE}_{\phi}\right)\left(1-0.50 .5 \text { fraction_bonding } \mathrm{s}_{\mathrm{s} / \mathrm{s}}\right) 0.50 .50 .5 \\
\text { Calculation of Pi Bonding Kinetic Energy Contributions }\end{array}$}} \\
\hline & & \\
\hline $\mathrm{KE}_{\text {net }} \mathrm{p} \pi \mathrm{p} \pi$ & 3.8520 & \\
\hline energy of resonating $\pi$ electron $\quad 0.5 \mathrm{KE}_{\text {net }} \mathrm{p} \pi \mathrm{p} \pi$ & 1.9260 & \\
\hline $\begin{array}{l}\text { total } \pi \text { resonance energy }=\text { resonance when both } \mathrm{C} \text { have } \mathrm{s} \text { up }\left(\text { to } \mathrm{p}_{\pi}\right) \\
+ \text { resonance when one } \mathrm{C} \text { has } \mathrm{s} \text { up and the other has } \mathrm{s} \text { down }= \\
2.0(1.0-0.50 .50 .5)(1.0-0.50 .50 .5) 0.5 \mathrm{KE}_{\text {net }} \mathrm{p} \pi \mathrm{-} \mathrm{p} \pi+ \\
2.0(1.0-0.50 .50 .5)(0.50 .50 .5) 0.5 \mathrm{KE}_{\text {net }} \mathrm{p} \pi \text { - } \mathrm{p} \pi\end{array}$ & 3.3706 & 3.3706 \\
\hline \multicolumn{3}{|l|}{ Potential Energy Terms } \\
\hline $\mathrm{C}$ nuclear- $\mathrm{C}$ nuclear repulsion energy & -386.4341 & -386.4341 \\
\hline $\begin{array}{l}\text { C nuclear to opposite C 1s orbitals energy } \\
\text { (4 of these) }\end{array}$ & 64.4058 & 257.6231 \\
\hline $\begin{array}{l}\text { C nuclear to opposite } 2 \mathrm{~s} \text { orbital energy } \\
2.0(1.0+0.50 .50 .5) \text { of these }\end{array}$ & 71.7966 & 143.5932 \\
\hline $\begin{array}{l}\text { C nuclear to opposite } 2 \mathrm{p}_{z} \text { orbital energy } \\
(2 \text { of these })\end{array}$ & 73.1481 & 146.2962 \\
\hline $\begin{array}{l}\text { C nuclear to opposite } 2 p_{x y} \text { orbital energy } \\
{[2.0(2.0-0.50 .50 .5) \text { of these }]}\end{array}$ & 58.8807 & 220.8026 \\
\hline $\mathrm{C}$ electron-C electron repulsions energy & -369.9797 & -369.9797 \\
\hline \multirow{2}{*}{$\begin{array}{l}\text { C electron affinity when } \mathrm{s} \text { is down }\left(0.5^{3}\right) \\
\text { when } \mathrm{s} \text { is up (estimated) }\end{array}$} & 1.262 & \\
\hline & 0.0 & \\
\hline $\begin{array}{l}\text { net affinity } \\
\text { resonance except when both } 2 \mathrm{~s} \text { are down }\left(1.0-0.5^{6}\right) \\
\text { C- for half of resonance }\end{array}$ & 0.0776 & 0.0776 \\
\hline $\mathrm{C}$ ionization potential & -11.2601 & \\
\hline $\mathrm{C}+$ when both s are down and for half of resonance & & -5.5421 \\
\hline $\begin{array}{l}\text { energy to raise } \mathrm{C} 2 \mathrm{~s} \text { to } 2 \mathrm{p} \\
\text { when in resonance, } 2 \mathrm{~s} \text { is promoted to } 2 \mathrm{p} \text { on each } \mathrm{C} \text { when } \mathrm{s} \text { is up } \\
\left(1.0-0.5^{3}\right) \text { on both } \mathrm{Cs}\left[2.0\left(1.0-0.5^{3}\right)\left(1.0-0.5^{3}\right)\right] \text { and } \\
\text { when one } \mathrm{C} \text { has s up and the other down }\left[2.00 .5^{3}\left(1.0-0.5^{3}\right)\right]\end{array}$ & -7.50 & \\
\hline $\begin{array}{l}\text { net energy to raise } \mathrm{C} 2 \mathrm{~s} \text { to } 2 \mathrm{p} \text { after allocating } 1.0 \mathrm{C} 2 \mathrm{~s} \text { to } 2 \mathrm{p} \text { to } \mathrm{HC} \text { bonds } \\
\text { (allocation is arbitrary) }\end{array}$ & -5.625 & -5.625 \\
\hline
\end{tabular}


Secondary $H-C$ Bond

Assumes primary HC bond length is $1.10 \AA$

Angle between the primary CC bond and the HC bond is $26.17^{\circ}$

$\cos 26.17^{\circ}=0.8975$

Secondary bond length is $2.1313 \AA$

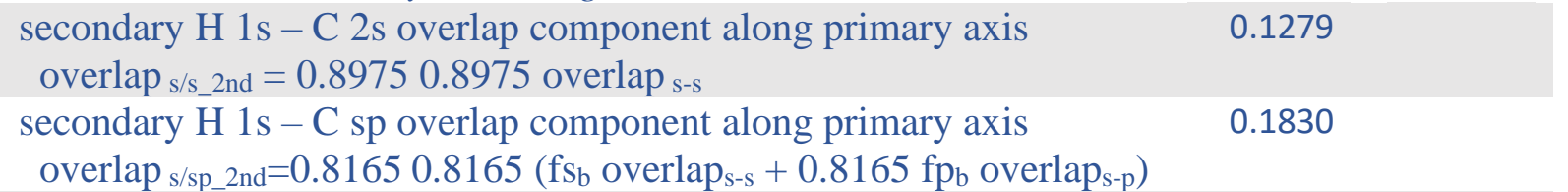

secondary $1 \mathrm{~s}$ to $2 \mathrm{~s}$ fraction_bonding (fraction_bonding s/s_2nd) 0.1134

fraction_bonding $\mathrm{s} / \mathrm{s} \_$2nd $_{2}=$ overlap $_{\mathrm{s} / \mathrm{s} \_2 n d} /\left(1+\right.$ overlap $\left._{\mathrm{s} / \mathrm{s} \_2 n d}\right)$

secondary $1 \mathrm{~s}$ to $\mathrm{sp}$ fraction_bonding (fraction_bonding s/sp_2nd)

0.1547

fraction_bonding s/sp_2nd $=$ overlap $_{\text {s/sp_2nd }} /(1+$ overlap s/sp_2nd $)$

Secondary fraction_bonding is reduced by previous, coincident

$1^{\text {st }}$ order bonding and previous coincident $2^{\text {nd }}$ order bonding.

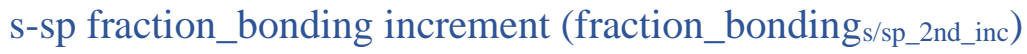

fraction_bonding s/sp_2nd_nc $=$

0.50 .75 (1- fraction_bonding $\left.{ }_{1 s t+p r e v 2 n d}\right)$ fraction_bonding ${ }_{s / s p \_2 n d}$

0.75 because s is up for 0.25

0.5 because increment is for component in one direction

fraction_bonding ${ }_{1 \text { st }}$ prev2nd adds previous secondary overlap

increments to fraction_bonding ${ }_{1 s t}$

s-sp overlap increment (overlaps/sp_2nd_inc)

overlap $s / s p \_2$ nd_inc $=$ fraction_bonding $s$ ssp_2nd_ind

(1.0- fraction_bonding $\mathrm{s}_{\mathrm{s} / \mathrm{s} \_2 \text { 2nd_inc) }}$

s-s fraction_bonding increment (fraction_bonding $s_{s / 2}$ 2nd_inc)

fraction_bonding $g_{s / s \_2 n d \_i n c}=$

0.50 .25 (1- 0.25 fraction_bonding s/s_lst) fraction_bonding s/s__nd $_{\text {s }}$

0.25 because $\mathrm{s}$ down for 0.25

s-s overlap increment (overlaps/s__nd_inc)

overlap $_{\mathrm{s} / \_\_2 \text { 2nd_inc }}=(0.5+0.50 .25)$ fraction_bonding $\mathrm{s}_{\mathrm{s} / \mathrm{s} \_ \text {2nd_ind }}$

(1.0- fraction_bonding $\mathrm{s}_{\mathrm{s} / \mathrm{s} \_ \text {2nd_inc) }}$

for rationale for $(0.5+0.50 .25)$ see discussion of asynchronous bonding.

Sum of secondary overlap increments over all four H C secondary bonds

kinetic energy of secondary s-sp bond $\left(2 \mathrm{KE}_{\mathrm{s} / \mathrm{sp}}\right)$ with s up

$\mathrm{KE}_{\mathrm{s} / \mathrm{sp}}=0.75$ (1.0-fraction_bonding $\left.{ }_{1 \mathrm{st}+2 \mathrm{nd}}\right)\left(1 /\left(1+\right.\right.$ overlap $\left.\left._{\text {total }}\right)\right)$

(f $\mathrm{fs}_{\mathrm{b}}$ overlap $\mathrm{p}_{\mathrm{s}-\mathrm{s}} \mathrm{KE}_{\text {net s-s}}+0.8165 \mathrm{fp}_{\mathrm{b}}$ overlap $\mathrm{p}_{\mathrm{s}-\mathrm{p}} \mathrm{KE}_{\text {net s-p}}$ )

kinetic energy of $\mathrm{H}-\mathrm{C}$ secondary bond ( $\mathrm{KE}_{\text {bond_2nd }}$ )

0.4841

0.4841

potential energy terms are included in $\mathrm{H} \mathrm{C}$ primary bond calculation 
Table VII. Components of the Primary $\mathrm{HC}$ bond in $\mathrm{H}_{2} \mathrm{CCH}_{2}$ Calculation at $1.1060 \AA$ (Energy in electron volts)

Terminology as in reference 1. Orbital scale factor for $\mathrm{H}$ is 1.09 and 1.05 for $\mathrm{C}$.

\begin{tabular}{|c|c|c|c|}
\hline Component & Value & $\begin{array}{l}\text { Overlap } \\
\text { change }\end{array}$ & $\begin{array}{l}\text { Energy } \\
(\mathrm{eV}) \\
\text { change }\end{array}$ \\
\hline \multicolumn{4}{|l|}{ Primary $H-C$ Bond } \\
\hline \multicolumn{4}{|l|}{$\mathrm{H}$ 1s bonding orbital is polarized as indicated in Table ? above. } \\
\hline overlap $_{\mathrm{s}-\mathrm{s}}$ & 0.6038 & & \\
\hline overlap s-p & 0.6815 & & \\
\hline $\begin{array}{l}\text { sigma overlap of primary orbitals }\left(\text { overlap }_{1 \mathrm{st}}\right) \\
\text { overlap }_{1 \mathrm{st}}=\mathrm{fs}_{\mathrm{b}} \text { overlap } \mathrm{p}_{\mathrm{s}-\mathrm{s}}+\mathrm{fp}_{\mathrm{b}} \text { overlap }-\mathrm{p} \\
\mathrm{fs}_{\mathrm{b}} \mathrm{fs}_{\mathrm{b}}=0.59375 \mathrm{fp}_{\mathrm{b}} \mathrm{fp}_{\mathrm{b}}=1.0-0.59375\end{array}$ & 0.8996 & 0.8996 & \\
\hline $\begin{array}{l}\left.\text { fraction_bonding (fraction_bonding }{ }_{1 \mathrm{st}}\right) \\
\quad \text { fraction_bonding } 1 \text { st }=\text { overlap }_{1 \mathrm{st}} /\left(1+\text { overlap }_{1 \mathrm{st}}\right)\end{array}$ & 0.4736 & & \\
\hline $\begin{array}{l}\text { kinetic energy of sigma orbital pair }\left(2 \mathrm{KE}_{\text {bond }}\right) \\
\mathrm{KE}_{\text {bond }}=\left(1 /\left(1+\text { overlap}_{1 \mathrm{st}}\right)\right)\left(\mathrm{fs}_{\mathrm{br}} \text { overlap } \mathrm{s-s}\right. \\
\mathrm{fp}_{\text {br }} \text { overlap } \mathrm{KE}_{\text {s-p }} \mathrm{KE}_{\text {net s }}+\mathrm{pz}\end{array}$ & 6.8019 & & 6.8019 \\
\hline $\begin{array}{l}\text { energy to make } \mathrm{H} 1 \mathrm{~s} \text { orthogonal to opposite } \mathrm{C} 1 \mathrm{~s}^{2} \\
\left(\mathrm{KE}_{\phi}-\mathrm{KE}_{\phi}\right) \text { where } \phi \text { is } \mathrm{H} 1 \mathrm{~s} \text { made orthogonal, } \phi \text { is } \mathrm{H} 1 \mathrm{~s}\end{array}$ & -10.2454 & & \\
\hline $\begin{array}{l}\text { energy to make } \mathrm{H} \text { 1s orthogonal to opposite } 1 \mathrm{~s}^{2} \text { when not bonding } \\
\mathrm{KE}_{\text {core }} \text { ortho } \\
=\left(\mathrm{KE}_{\phi}-\mathrm{KE}_{\phi}\right)(1-0.5)\end{array}$ & -5.1227 & & -5.1227 \\
\hline nuclear-nuclear repulsion energy & -78.1189 & & -78.1189 \\
\hline $\mathrm{C}$ nuclear to $\mathrm{H} 1$ s energy & 83.8000 & & 83.8000 \\
\hline H nuclear to opposite two C 1 s orbitals energy & 26.0397 & & 26.0397 \\
\hline H nuclear to opposite 2 s orbital energy & 14.2464 & & 14.2464 \\
\hline $\mathrm{H}$ nuclear to opposite $2 \mathrm{p}_{z}$ orbital energy & 14.9261 & & 14.9261 \\
\hline $\mathrm{H}$ nuclear to opposite two $2 \mathrm{p}_{\mathrm{xy}}$ orbital energy & 21.4100 & & 21.4100 \\
\hline $\mathrm{H}$ electron-C electron repulsions energy & -77.7397 & & -77.7397 \\
\hline energy to compress/polarize $\mathrm{H}$ & -0.641 & & -0.641 \\
\hline $\begin{array}{l}\text { energy to raise } \mathrm{C} 2 \mathrm{~s} \text { to } 2 \mathrm{p} \\
0.25 \text { of } \mathrm{s} \text { to } \mathrm{p} \text { energy (allocation to bonds arbitrary, see Table?) }\end{array}$ & -1.87 & & -1.87 \\
\hline
\end{tabular}


Secondary $H-H$ Bond

$\cos \angle$ between the $H H$ bond and the primary $H C$ bond $=0.854$

Secondary bond length is $1.890 \AA$

secondary $\mathrm{H} 1 \mathrm{~s}-\mathrm{H}$ 1s overlap (secondary overlap s-s) )

0.2762

secondary $\mathrm{H}-\mathrm{H}$ sigma overlap along primary axis (overlap 2 nd

0.2014

overlap $_{2 \text { nd }}=0.8540 .854$ overlap $_{\text {s-s }}$

secondary fraction_bonding (fraction_bonding 2 nd $)$

0.1676

fraction_bonding 2 nd $=$ overlap $_{2 \text { nd }} /\left(1+\right.$ overlap$\left._{2 n d}\right)$

secondary fraction_bonding increment (fraction_bonding 2nd_inc)

0.0441

fraction_bonding 2 nd_inc $=0.5$ (1- fraction_bonding $\left.{ }_{1 \mathrm{st}}\right)$

fraction_bonding 2 nd .

secondary fraction_bonding is

reduced by previous, coincident $1^{\text {st }}$ order bonding.

0.5 because secondary spans 2 primary.

secondary overlap increment

$0.0462 \quad 0.0462$

secondary overlap $=$

fraction_bonding 2nd_inc/(1-fraction_bonding 2nd_inc)

kinetic energy of $\mathrm{H}-\mathrm{H}$ bond ( $\left.\mathrm{KE}_{\text {bond_2nd }}\right)$

0.3061

$\mathrm{KE}_{\text {bond_2nd }}=\left(\right.$ secondary overlap $_{\text {s-s }} /\left(1.0+\right.$ overlap$\left.\left._{\text {total }}\right)\right) \mathrm{KE}_{\text {net s-s }}$

overlap $_{\text {total }}=$ overlap $_{1 \mathrm{st}}+$ overlap $_{2 \text { nd }}$

[not (2.0 KE $\left.\mathrm{KEnd}_{\text {bond }}\right)$ as this energy is shared with the other $\mathrm{HC}$ bond]

secondary kinetic energy increment (KE $\left.\mathrm{K}_{\text {bond_2nd_inc }}\right)$

0.1740

0.1740

$\mathrm{KE}_{\text {bond_2nd_inc }}=(1-$ fraction_bonding $1 \mathrm{st}) \mathrm{KE}_{\text {bond_2nd }}$

Secondary $\mathrm{KE}_{\text {bond_2nd }}$ is reduced by previous, coincident

$1^{\text {st }}$ order bonding.

$\mathrm{H}$ nuclear-H nuclear repulsion energy

$-7.6193$

$\mathrm{H}$ nuclear to opposite $\mathrm{H}$ 1s (2 single nuclear to opposite)

16.1965

total $\mathrm{H} 1 \mathrm{~s}$ to $\mathrm{H}$ 1s electron - electron repulsion

$-8.4946$

total potential energy terms

0.0826

net potential energy

0.0413

0.0413

0.5 total because energy is shared with adjacent $\mathrm{HC}$ bond

total secondary energy

0.2153

Secondary $\mathrm{H}-\mathrm{C}$ Bond

$\cos \angle$ between the $C=C$ bond and this $H C$ bond $=0.844$

$\cos \angle$ between the primary $\mathrm{HC}$ bond and this $\mathrm{HC}$ bond $=0.897$

Secondary bond length is $2.134 \AA$

sigma overlap along primary axis (overlap 2 nd)

0.1612

overlap $_{2 \text { nd }}=0.8440 .844\left(\mathrm{fs}_{\mathrm{b}}\right.$ overlap $_{\mathrm{s}-\mathrm{s}}+0.897 \mathrm{fp}_{\mathrm{b}}$ overlap $\left._{\mathrm{s}-\mathrm{p}}\right)$

$\mathrm{fs}_{\mathrm{b}} \mathrm{fs}_{\mathrm{b}}=0.8125 \mathrm{fp}_{\mathrm{b}} \mathrm{fp}_{\mathrm{b}}=1.0-0.8125$ 


\begin{tabular}{|c|c|c|c|}
\hline $\begin{array}{l}\text { secondary fraction_bonding }(\text { fraction_bonding } 2 \text { nd }) \\
\quad \text { fraction_bonding } 2 \text { nd }=\text { overlap }_{2 n d} /\left(1+\text { overlap }_{2 n d}\right)\end{array}$ & 0.1388 & & \\
\hline 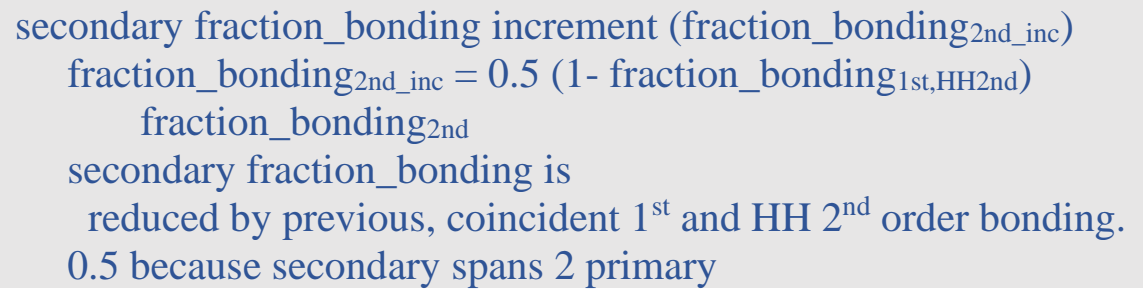 & 0.0357 & & \\
\hline $\begin{array}{l}\text { secondary overlap increment } \\
\text { secondary overlap = } \\
\quad \text { fraction_bonding } 2 \text { nd_inc } /(1-\text { fraction_bonding } 2 \text { nd_inc })\end{array}$ & 0.0370 & 0.0370 & \\
\hline 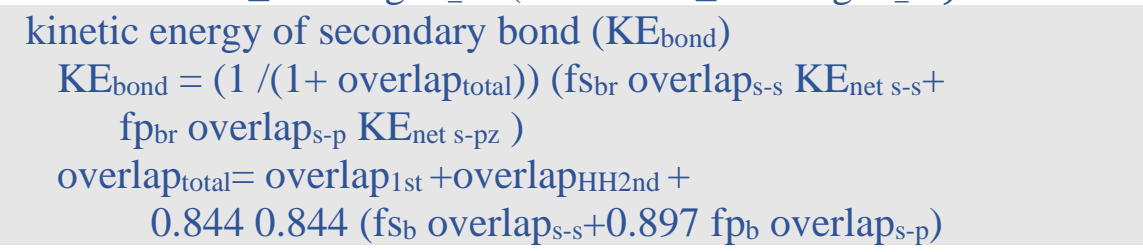 & 0.2167 & & \\
\hline 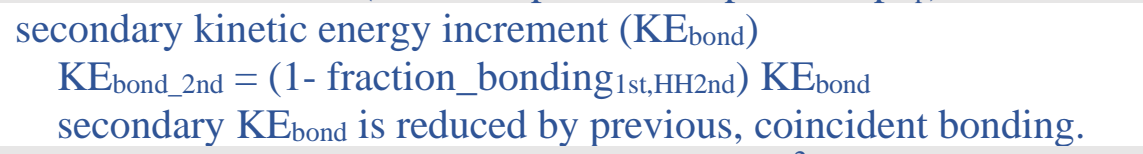 & 0.1114 & & 0.1114 \\
\hline $\begin{array}{l}\text { energy to make } \mathrm{H} 1 \mathrm{~s} \text { orthogonal to opposite } 1 \mathrm{~s}^{2} \text { when not bonding } \\
\mathrm{KE}_{\text {core_ortho }}=\left(\mathrm{KE}_{\phi}-\mathrm{KE}_{\phi}\right)(1-0.5)\end{array}$ & -0.0565 & & -0.0565 \\
\hline net potential energy terms & 0.1622 & & 0.1622 \\
\hline $\begin{array}{c}\text { Tertiary } H-H \text { Bond (adjacent, straight across) } \\
\cos \angle \text { between the } H H \text { bond and the primary } H C \text { bond }=0.52 \\
\text { Tertiary bond length is } 2.489 \AA\end{array}$ & & & \\
\hline tertiary $\mathrm{H} 1 \mathrm{~s}-\mathrm{H}$ 1s overlap (secondary overlap s-s $_{\text {) }}$ & 0.0984 & & \\
\hline $\begin{array}{l}\text { tertiary } \mathrm{H}-\mathrm{H} \text { overlap along primary axis (overlap } 3 \text { nd }) \\
\text { overlap }_{3 \mathrm{rd}}=0.520 .52 \text { overlap }_{\mathrm{s}-\mathrm{s}}\end{array}$ & 0.0266 & & \\
\hline $\begin{array}{l}\text { tertiary fraction_bonding }(\text { fraction_bonding } 3 \text { rd }) \\
\text { fraction_bonding } 3 \text { rrd }=\text { overlap } 3 \text { rd } /\left(1+\text { overlap }_{3 \mathrm{rd}}\right)\end{array}$ & 0.0259 & & \\
\hline 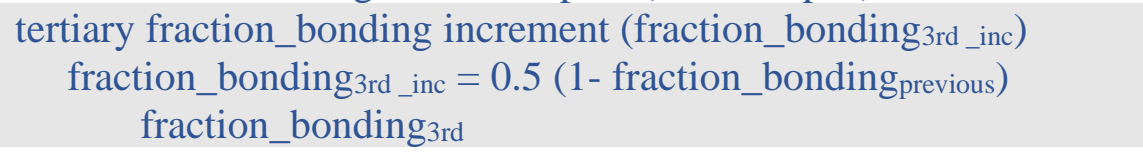 & 0.0066 & & \\
\hline tertiary overlap increment & 0.0066 & 0.0066 & \\
\hline $\begin{array}{l}\text { tertiary kinetic energy increment }\left(\mathrm{KE}_{\text {bond_3rd }}\right) \\
\mathrm{KE}_{\text {bond_3rd }}=(1-\text { fraction_bonding } \\
\quad\left(\text { overlap }_{\text {s-s }} \mathrm{KE}_{\text {net s-s }}\right)\end{array}$ & 0.0199 & & 0.0199 \\
\hline net of potential energy terms & 0.0043 & & 0.0043 \\
\hline $\begin{array}{c}\text { Tertiary } H-H \text { Bond (opposite) } \\
\cos \angle \text { between the } H H \text { bond and the primary } H C \text { bond }=0.930 \\
\cos \angle \text { between the } H H \text { bond and the CC bond }=0.797 \\
\text { Tertiary bond length is } 3.125 \AA\end{array}$ & & & \\
\hline
\end{tabular}




\begin{tabular}{|c|c|c|c|}
\hline tertiary H 1s $-\mathrm{H}$ 1s overlap (secondary overlap ${ }_{\mathrm{s}-\mathrm{s}}$ ) & 0.0483 & & \\
\hline $\begin{array}{c}\text { tertiary } \mathrm{H}-\mathrm{H} \text { overlap along primary axis }\left(\text { overlap }_{3 \mathrm{nd}}\right) \\
\text { overlap }_{3 \mathrm{rd}}=0.930 .93 \text { overlap }_{\mathrm{s}-\mathrm{s}}\end{array}$ & 0.0418 & & \\
\hline $\begin{array}{l}\text { tertiary fraction_bonding (fraction_bonding } 3 \text { rd }) \\
\text { fraction_bonding } 3 \text { rd }=\text { overlap } 3 \text { rd } /\left(1+\text { overlap }_{3 \mathrm{rd}}\right)\end{array}$ & 0.0401 & & \\
\hline $\begin{array}{l}\left.\text { tertiary fraction_bonding increment (fraction_bonding }{ }_{3 r d} \text { _inc }\right) \\
\text { fraction_bonding } 3 \text { 3rd_inc }=0.5(1-\text { fraction_bonding } \\
\text { fraction_bondious })\end{array}$ & 0.0101 & & \\
\hline tertiary overlap increment & 0.0102 & 0.0102 & \\
\hline $\begin{array}{l}\text { tertiary kinetic energy increment }\left(\mathrm{KE}_{\text {bond_3rd }}\right) \\
\mathrm{KE}_{\text {bond_3rd }}=(1-\text { fraction_bonding } \\
\text { (overevious })\left(1 /\left(1+\text { overlap }_{\text {s-s }} K_{\text {total }}\right)\right) \\
\left.E_{\text {net s-s }}\right)\end{array}$ & 0.0045 & & 0.0045 \\
\hline \multicolumn{4}{|l|}{ net of potential energy terms } \\
\hline Totals & & 0.9996 & 4.19 \\
\hline
\end{tabular}

\section{Acetylene (HCCH)}

The s hybrid orbital coefficient for the $\mathrm{CC}$ bond in acetylene is set to 0.875 consistent with the analysis summarized in Table I. The CC bond in acetylene is dual to the extent that the HC bonds on each $\mathrm{C}$ are both bonding. The calculated CC bond length is $1.195 \AA$, in good agreement with the observed bond length of $1.203 \AA$. The calculated total of the bond energies in ethylene is $17.20 \mathrm{eV}$. This is to be compared to the observed value of $17.01 \mathrm{eV}$.

When either of the two $C$ sigma bonds is not bonding the $C$ configuration is $2 \mathrm{~s} 2 \mathrm{p}_{\mathrm{z}} 2 \mathrm{p}_{\pi}{ }^{2}$. When both Cs have this configuration there are two pi resonances and a pi bond. When either or both Cs have the $2 s^{2} 2 p_{z} 2 p_{\pi}$ configuration there is a single pi resonance. (See note on Table V concerning the counting of bonds.)

\section{Benzene $\left(\mathrm{C}_{6} \mathrm{H}_{6}\right)$}

The s orbital coefficient for the $\mathrm{CC}$ bond in benzene is set to 0.729 . Were there no geometric constraints, the s hybrid orbital coefficient would be 0.75 as described in Table IV. In benzene, however, the two favored $\mathrm{C}$ bonding orbitals have a geometric component which faces the other. Favored hybrid orbitals acquire s character by taking it from an opposite hybrid orbital. The common component of favoritism between facing orbitals must be omitted. The two favored orbitals face each other (depart from the normal) by 30 degrees $(120-90=30)$. The normal component is 60 degrees. The asymmetry is limited by 0.25 since $\cos 30 \cos 30=0.25$. $0.6667+0.75(0.75-0.6667)=0.72917$. $(0.6667$ would be the s hybrid orbital coefficient were no $\mathrm{C}$ bond preferred.)

The $\mathrm{CC}$ bond in benzene is dual to the extent that the two adjacent $\mathrm{CC}$ are both bonding (adjusted for the extent that the s s bonds are simultaneous with the s s bonds of the adjacent 
bonds). The calculated CC bond length in benzene is $1.400 \AA$, in good agreement with the observed bond length of $1.399 \AA$.

Pi resonance in benzene is limited to $1 / 3$ because adjacent bonds cannot resonate. Adjacent resonance raises the possibility of a doubly charged species that is very energetically unfavorable. Non-resonance pi bonds form for $2 / 3$. Both pi resonance and non-resonance pi bonds require that $\mathrm{C}$ have the $2 \mathrm{~s} 2 \mathrm{p}_{\mathrm{z}} 2 \mathrm{p}_{\perp} 2 \mathrm{p}_{\pi}$ configuration (any sigma bond not-bonding). For a nonresonance pi bond both sides must have this configuration. Non-resonance pi bonds are reduced to account for simultaneous pi bonding from both sides of the $\mathrm{C}$. The calculated total of the bond energies in benzene is $57.61 \mathrm{eV}$. This is to be compared to the observed value of $57.25 \mathrm{eV}$.

\section{E. Allene $\left(\mathrm{H}_{2} \mathrm{CCCH}_{2}\right)$}

The s hybrid orbital coefficient for the end Cs in the CC bonds in allene is set to 0.8125 consistent with the analysis summarized in Table II (same as in ethylene). The s hybrid orbital coefficient for the central $\mathrm{C}$ in the $\mathrm{CC}$ bonds in allene is set to 0.75 consistent with the analysis summarized in Table I. The $\mathrm{CC}$ bond in allene is dual to the extent that the two adjacent $\mathrm{HC}$ are both bonding and the adjacent $\mathrm{CC}$ bond is also bonding. The calculated $\mathrm{CC}$ bond length in allene is $1.312 \AA$, in good agreement with the observed bond length of $1.308 \AA$.

Each $\mathrm{CC}$ bond in allene has a pi bond to the extent that both Cs have the $2 \mathrm{~s} 2 \mathrm{p}_{\mathrm{z}} 2 \mathrm{p}^{2}$ configuration. The central $\mathrm{C}$ has this configuration when either $\mathrm{CC}$ sigma bond is not bonding. The end $\mathrm{C}$ has this configuration when either of the $\mathrm{HC}$ bonds or the $\mathrm{CC}$ bond is not bonding. There is a half pi bond when the end $C$ has the $2 s 2 p_{z} 2 p^{2}$ configuration and the central $C$ has the $2 s^{2} 2 p_{z} 2 p$ configuration. (Half here because there is only a single p orbital in the central C's x-y plane.) The half pi bond is reduced to account for simultaneous pi bonding from both sides of the central $\mathrm{C}$. The calculated total of the bond energies in allene is $29.12 \mathrm{eV}$. This is to be compared to the observed value of $29.33 \mathrm{eV}$.

\section{F. Hydrogen Cyanide (HCN)}

The $\mathrm{C}$ s hybrid orbital coefficient for the $\mathrm{CN}$ bond in hydrogen cyanide is set to 0.875 consistent with the analysis summarized in Table $\mathrm{I}$ (the same as the $\mathrm{C}$ in acetylene). The $\mathrm{N} \mathrm{s}$ hybrid orbital coefficient is set to meet the valence orthogonality requirements $(0.59)$. The $\mathrm{CN}$ bond in hydrogen cyanide is dual to the extent that the $\mathrm{HC}$ bond is bonding (similar to acetylene). The calculated CN bond length in hydrogen cyanide is $1.156 \AA$, in good agreement with the observed bond length of $1.153 \AA$.

$\mathrm{CN}$ has a pi resonance of the form $[\mathrm{CN}, \mathrm{C}+\mathrm{N}-]$. Since the potential energy associated with the $\mathrm{N}$ - configuration $2 \mathrm{~s}^{2} 2 \mathrm{p}_{z} 2 \mathrm{p}_{\pi}{ }^{3}$ in $\mathrm{C}+\mathrm{N}$ - is more favorable than the potential energy associated with the $\mathrm{N}$ - configuration $2 \mathrm{sp}_{\mathrm{o}} 2 \mathrm{~s} 2 \mathrm{p}_{\mathrm{z}} 2 \mathrm{p}_{\pi}{ }^{3}$ (2s $\mathrm{p}_{\mathrm{o}}$ is the opposing orbital which forms to the extent that the $\mathrm{CN}$ sigma bond is not bonding.), the pi resonance only occurs to the extent that the $\mathrm{CN}$ sigma bond is bonding (0.5) and $\mathrm{N}$ - has the favorable configuration. The relative populations of the two species $[\mathrm{CN}, \mathrm{C}+\mathrm{N}-]$ are $[0.75,0.25]$. To the extent that the $\mathrm{CN}$ bond is resonating there is a second half pi bond (only one side bonds) bond for 0.5 (when not $\mathrm{C}+\mathrm{N}-$ ). There is an additional (non-resonating) pi bond when the C configuration is $\mathrm{C} 2 \mathrm{~s} 2 \mathrm{p}_{z} 2 \mathrm{p}_{\pi}{ }^{2}$. To the extent that the CN bond is not resonating (0.5), there is a pi bond plus a second when the $\mathrm{C}$ configuration is $2 \mathrm{~s} 2 \mathrm{p}_{\mathrm{z}} 2 \mathrm{p}_{\pi}{ }^{2}$. 
The energy of the resonance species $[\mathrm{C}+\mathrm{N}-]$ is taken as the sum of the first ionization potential of $\mathrm{C}$ plus the electron affinity of $\mathrm{N}$. The electron affinity of $\mathrm{N}$ is taken as $-0.15 \mathrm{eV}$.

The calculated total of the bond energies in hydrogen cyanide is $12.98 \mathrm{eV}$. This is to be compared to the observed value of $13.25 \mathrm{eV}$.

If one assumes that the $\mathrm{CN}$ pi resonance is unconstrained by the $\mathrm{N}$ - configuration, and the relative populations of the two species $[\mathrm{CN}, \mathrm{C}+\mathrm{N}-]$ are $[0.5,0.5]$, the resulting molecular energy would be reduced by about $0.55 \mathrm{eV}$.

The calculated dipole moment is $3.04 \mathrm{D}$. This is to be compared to the observed value of $2.985 \mathrm{D}$. The dipole moment is the sum of the $\mathrm{HC}$ bond dipole and the $\mathrm{CN}$ bond dipole. The $\mathrm{HC}$ bond has an associated dipole moment because the $\mathrm{H}$ is polarized in the bond.

\section{G. Formaldehyde $\left(\mathrm{H}_{2} \mathrm{CO}\right)$}

The $\mathrm{C}$ s hybrid orbital coefficient for the $\mathrm{CO}$ bond in formaldehyde is set to 0.8125 consistent with the analysis summarized in Table II (the same as the $\mathrm{C}$ in ethylene). The $\mathrm{O} s$ hybrid orbital coefficient is set to meet the valence orthogonality requirements $(0.60)$. The $\mathrm{CO}$ bond in formaldehyde is dual to the extent that both $\mathrm{HC}$ bonds are bonding (similar to ethylene). The calculated CO bond length in formaldehyde is $1.208 \AA$, in good agreement with the observed bond length of $1.208 \AA$.

$\mathrm{CO}$ has a pi resonance of the form [CO,C+O-]. Since the potential energy associated with the O- configuration $2 \mathrm{~s}^{2} 2 \mathrm{p}_{\mathrm{z}} 2 \mathrm{p}_{\pi}{ }^{4}$ in $\mathrm{C}+\mathrm{O}$ - is more favorable than the potential energy associated with the $\mathrm{O}$ - configuration $2 \mathrm{sp}_{\mathrm{o}} 2 \mathrm{~s} 2 \mathrm{p}_{\mathrm{z}} 2 \mathrm{p}_{\pi}$, the pi resonance only occurs to the extent that the CO sigma bond is bonding (0.5) and the $\mathrm{O}$ - thus has the favorable configuration. This resonance is analogous to the resonance in $\mathrm{HCN}$. The $\mathrm{CO}$ resonance only occurs to the extent that $\mathrm{C}$ has the $2 \mathrm{~s} 2 \mathrm{p}_{z} 2 \mathrm{p} 2 \mathrm{p}_{\pi}$ configuration which occurs when any of the three sigma bonds to $\mathrm{C}$ are not bonding $(0.875)$. To the extent that the $\mathrm{CO}$ pi bond is resonating there is also a second half pi bond (only one side bonds) bond for 0.5 (when not $\mathrm{C}+\mathrm{O}-$ ). To the extent that the $\mathrm{CO}$ pi bond is not resonating, and when the $C$ configuration is $2 \mathrm{~s} 2 \mathrm{p}_{\mathrm{z}} 2 \mathrm{p}_{\pi}{ }^{2}$, there is a pi bond $(0.875-0.4375)$.

The energy of the resonance species $[\mathrm{C}+\mathrm{O}-]$ is the sum of the first ionization potential of $\mathrm{C}$ plus the electron affinity of $\mathrm{O}$. The electron affinity of $\mathrm{O}$ is taken as $1.46 \mathrm{eV}$.

The calculated total of the bond energies in formaldehyde is $15.76 \mathrm{eV}$. This is to be compared to the observed value of $15.59 \mathrm{eV}$.

The calculated dipole moment is $2.51 \mathrm{D}$. This is to be compared to the observed value of $2.33 \mathrm{D}$. The dipole moment is the sum of the $\mathrm{HC}$ bond dipoles and the $\mathrm{CO}$ bond dipole. The $\mathrm{HC}$ bonds have an associated dipole moment because the $\mathrm{H}$ is polarized in the bond. The dipole moment calculation is subject to any error in the $\mathrm{HC}$ polarization.

\section{H. Floromethane $\left(\mathrm{H}_{3} \mathrm{CF}\right)$}

The $\mathrm{C}$ s hybrid orbital coefficient for the CF bond in floromethane is set to 0.5 , the same as in methane. The CF bond consists of overlaps of sp hybrid orbitals on $\mathrm{C}$ with sp hybrids on $\mathrm{F}$. The $\mathrm{CF}$ bond in $\mathrm{H}_{3} \mathrm{CF}$ has a sigma resonance of the form [CF, $\left.\mathrm{C}+\mathrm{F}-\right]$. The $\mathrm{CF}$ bond resonates 
only to the extent that the $\mathrm{F}$ has the configuration $2 \mathrm{sp}_{0} 2 \mathrm{~s} 2 \mathrm{p}_{z} 2 \mathrm{p}_{\perp}{ }^{4}(0.5)$. The relative populations of the two species [ $\left.\mathrm{H}_{3} \mathrm{CF}, \mathrm{H}_{3} \mathrm{C}+\mathrm{F}-\right]$ are $[0.75,0.25]$.

The sigma resonance has an effect on the overall sigma bond overlap. When $\mathrm{C}+\mathrm{F}-$, the $\mathrm{F}-\mathrm{has}$ two sigma orbitals, the $\mathrm{C}+$ none. The two F- orbitals bond, F- to $\mathrm{C}+$, in parallel. Since this is an overlap only in one direction, right to left, there is one-half serial bond and one-half in parallel (parallel bond). When $\mathrm{CF}$, there is the typical, serial, $\mathrm{CF}$ bond. Combining the $\mathrm{CF}$ and $\mathrm{C}+\mathrm{F}$ - contributions, there results a bond which is 1.0-0.125 serial and 0.125 parallel. The distinction between serial and parallel is important because, in the determination of overall overlap, the serial overlaps are summed, serial fraction_bonding calculated, which is then added to the parallel fraction_bonding (See reference 1.). Because, when bonds are parallel, two fraction_bonding contributions are summed, rather than the overlaps summed, parallel bonding has the effect of increasing the overall overlap, thereby increasing the bond length. The calculated CF bond length in floromethane is $1.377 \AA$, in good agreement with the observed bond length of $1.382 \AA$. Consistent with resonance description above, the $\mathrm{CF}$ bond in $\mathrm{H}_{3} \mathrm{CF}$ has the resonance kinetic energy associated with the 0.5 sigma resonance $(20.25)$. (The resonance kinetic energy is calculated as if the overlap were 1.0. See reference 1.) The balance of the kinetic energy is that of a non-resonance bond (2.0) less the kinetic energy associated with the fraction as $\mathrm{C}+\mathrm{F}$ - and the complementary resonance species $\mathrm{CF}(20.25)$.

The energy of the resonance species $[\mathrm{C}+\mathrm{F}-]$ is the sum of the first ionization potential of $\mathrm{C}$ plus the electron affinity of $\mathrm{F}$. The electron affinity of $\mathrm{F}$ is taken as $3.40 \mathrm{eV}$. It is important to note that the energy required to promote $\mathrm{s}$ to $\mathrm{p}$ in $\mathrm{C}+$ must be increased by $\mathrm{fs}_{\mathrm{bc}} \mathrm{fs}_{\mathrm{bc}}$ times the $\mathrm{C}$ stop value for $\mathrm{C}+$. This is because a p orbital is removed in $\mathrm{C}$ ionization whereas an sp orbital is removed to form $\mathrm{C}+$ in $\mathrm{H}_{3} \mathrm{C}+\mathrm{F}-$. The calculated total of the bond energies in floromethane is $17.58 \mathrm{eV}$. This is to be compared to the observed value of $17.44 \mathrm{eV}$.

The calculated dipole moment is $2.73 \mathrm{D}$. This is to be compared to the observed value of $2.858 \mathrm{D}$. The dipole moment is the sum of the $\mathrm{HC}$ bond dipoles and the $\mathrm{CF}$ bond dipole. As mentioned with respect to formaldehyde, the dipole moment calculation is subject to any error in the HC polarization.

\section{Tetrafloromethane ( $\left.\mathrm{CF}_{4}\right)$}

The $\mathrm{C}$ s hybrid orbital coefficient for the $\mathrm{CF}$ bond in tetrafloromethane is set to 0.5 , the same as in methane. As in $\mathrm{H}_{3} \mathrm{CF}$, the $\mathrm{CF}$ bonds consist of overlaps of sp hybrid orbitals on $\mathrm{C}$ with sp hybrids on $\mathrm{F}$. The $\mathrm{CF}$ bonds in $\mathrm{CF}_{4}$ have a sigma resonance of the form $\left[\mathrm{C}+\mathrm{F}^{-} \mathrm{FFF}, \mathrm{C}+\mathrm{FF}-\right.$ $\left.\mathrm{FF}, \mathrm{C}+\mathrm{FFF}^{-} \mathrm{F}, \mathrm{C}+\mathrm{FFFF}^{-}\right]$. The $\mathrm{CF}$ bond resonates only to the extent that the $\mathrm{F}$ has the configuration $2 \mathrm{sp}_{\mathrm{o}} 2 \mathrm{~s} 2 \mathrm{p}_{\mathrm{z}} 2 \mathrm{p}_{\perp}{ }^{4}(0.5)$. The central $\mathrm{C}$ has a single positive charge. Each $\mathrm{F}$ has a negative charge of 0.25 . An electron resonates among the four Fs.

The sigma resonance has the same effect on the sigma bond overlap of each of the CF bonds in $\mathrm{CF}_{4}$ as it did on the $\mathrm{CF}$ bond in $\mathrm{H}_{3} \mathrm{CF}$. As with the $\mathrm{CF}$ bond in $\mathrm{H}_{3} \mathrm{CF}$, there results a sigma bond which is 1.0-0.125 serial and 0.125 parallel. The calculated CF bond length in tetrafloromethane is $1.318 \AA$, in good agreement with the observed bond length of $1.323 \AA$.

The resonance electron resonates from one $\mathrm{F}$ to another $\mathrm{F}$. Therefore, the $\mathrm{CF}$ bond in $\mathrm{CF}_{4}$ has twice the resonance kinetic energy as that associated with the sigma resonance for the $\mathrm{CF}$ bond in $\mathrm{H}_{3} \mathrm{CF}$. The resonance kinetic energy is 220.25 . The balance of the kinetic energy is that of a non-resonance bond (2.0) less the kinetic energy associated with the fraction as $\mathrm{C}+\mathrm{F}$ - and 
the two complementary resonance species $\mathrm{CF}(30.25)$. The calculated bond energy in tetrafloromethane is $5.06 \mathrm{eV}$. This is to be compared to the observed value of $5.089 \mathrm{eV}$.

\section{J. Floromethylidyne (CF)}

The bond in $\mathrm{CF}$ is different from the $\mathrm{CF}$ bonds in $\mathrm{H}_{3} \mathrm{CF}$ and $\mathrm{CF}_{4}$ for several reasons: the extra s sigma bonding electron on $\mathrm{C}$ permits dual bonding, the additional sigma bonding orbital must be made orthogonal to the F- bonding orbitals, and the axial symmetry of CF permits pi interactions. $\mathrm{CF}$ has a sigma resonance of the form $\left[\mathrm{CF}, \mathrm{C}+\mathrm{F}^{-}\right]$. As in $\mathrm{H}_{3} \mathrm{CF}$ and $\mathrm{CF}_{4}$, the $\mathrm{CF}$ bond resonates only to the extent that the $\mathrm{F}$ has the configuration $2 \mathrm{sp}_{o} 2 \mathrm{~s} 2 \mathrm{p}_{z} 2 \mathrm{p}_{\perp}{ }^{4}(0.5)$. The relative populations of the two species [CF,C+F-] are [0.75,0.25]. When $\mathrm{CF}(0.75)$ there is a dual bond made up of sp to sp and s to sp hybrid orbital components. When $\mathrm{C}+\mathrm{F}-$, there is a left to right ( 0.5 contribution) dual bond made up of two s to sp hybrid orbital components. Also, there is a right to left $(0.5$ contribution) single s to sp hybrid orbital bond. As in $\mathrm{H}_{3} \mathrm{CF}$ and $\mathrm{CF}_{4}$, there is also a one-half (left to right) parallel sp to sp bond when $\mathrm{C}+\mathrm{F}-$. The calculated $\mathrm{CF}$ bond length in floromethylidyne is $1.269 \AA$, in good agreement with the observed bond length of $1.272 \AA$.

Consistent with resonance description above, the $\mathrm{CF}$ bond has the resonance kinetic energy associated with the 0.5 sigma resonance $(20.25)$. The balance of the kinetic energy is that of a non-resonance bond consistent with the overlaps described above.

Because CF has axial symmetry there are pi interactions. CF has a single pi bond. When $\mathrm{F}$ has the configuration $2 \mathrm{sp}_{\mathrm{o}} 2 \mathrm{~s} 2 \mathrm{p}_{\mathrm{z}} 2 \mathrm{p}_{\pi}{ }^{4}$ one of the $\mathrm{F} \mathrm{p}_{\pi}$ orbitals must be made orthogonal to the $\mathrm{C} \mathrm{p}_{\pi}$ orbital. One of the $\mathrm{F}-\mathrm{p}_{\pi}$ orbitals must be made orthogonal to the $\mathrm{C} \mathrm{p}_{\pi}$ orbital when F-.

To meet the valence orthogonality requirements when $\mathrm{C}+\mathrm{F}-$, one of the $\mathrm{F}$ - sigma orbitals must be made orthogonal to the residual s orbital on the $\mathrm{C}+$ to the extent that the bond is not bonding (0.5) (An $2 \mathrm{sp}_{\mathrm{o}}^{2}$ configuration is energetically unfavorable.). The calculated bond energy in floromethylidyne is $5.40 \mathrm{eV}$. This is to be compared to the observed value of $5.33 \pm 0.11 \mathrm{eV}$.

The calculated dipole moment is $0.63 \mathrm{D}$. This is to be compared to the observed value of $0.645 \mathrm{D}$.

\section{CONCLUSION}

The results presented here as well as previous results ${ }^{1,6}$ provide strong support for the efficacy of combined orbital theory of chemical bonding. The combined orbital theory does not assume that the bonding orbitals of two bonding atoms are completely distinguishable. When quantum chemical calculations were initially performed in the 1930's, calculations which did not assume that the bonding orbitals were distinguishable were not possible. It is only in the last ten or fifteen years that the sufficient processing power has been available to accurately perform the numerical calculations which are an essential part of combined orbital calculations. Independent research is needed to validate, or refute, the combined orbital approach.

\footnotetext{
${ }^{1}$ P.B. Merrithew, ChemRxiv. [Preprint] https://doi.org/10.26434/chemRxiv.13049927 (2020).

${ }^{2}$ W.E. Duncanson and C.A. Coulson, Proc.Roy.Soc. (Edinburgh), 62, 37 (1944).

${ }^{3}$ W.M. Hayes, Editor-In-Chief, CRC Handbook of Chemistry and Physics $95^{\text {th }}$ Edition, Section 5 pp 18-42, CRC Press (2014).
} 
${ }^{4}$ W.M. Hayes, Editor-In-Chief, CRC Handbook of Chemistry and Physics $95^{\text {th }}$ Edition, Section 9 pp 31-47, CRC Press (2014).

${ }^{5}$ W.M. Hayes, Editor-In-Chief, CRC Handbook of Chemistry and Physics $95^{\text {th }}$ Edition, Section 9 pp 51-59, CRC Press (2014).

${ }^{6}$ P.B. Merrithew, ChemRxiv. [Preprint] https://doi.org/10.26434/chemRxiv.13013936 (2021). 